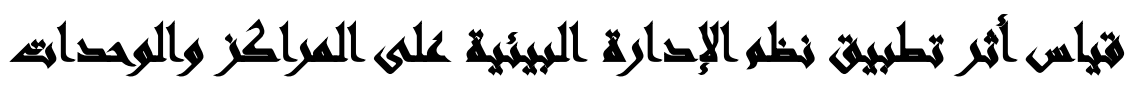

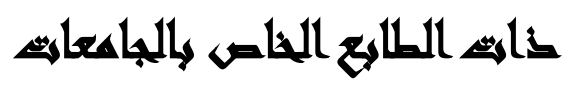

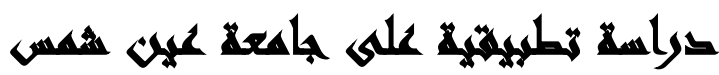

\section{[iv]}

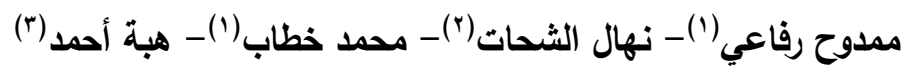

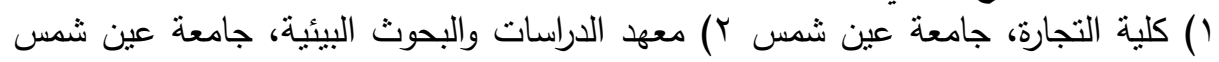

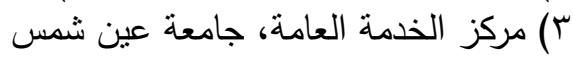

\section{المهريختى}

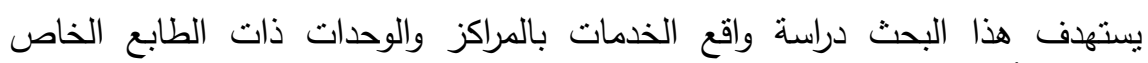

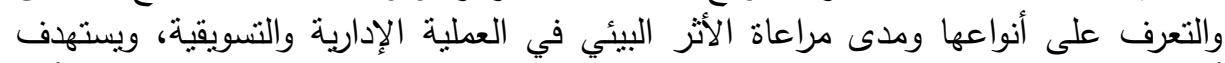

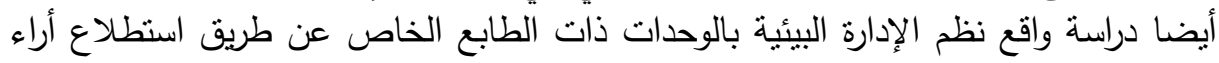

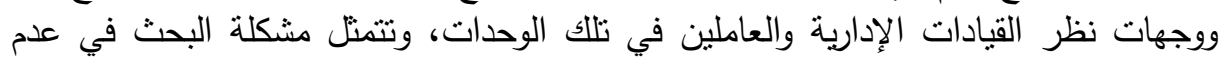

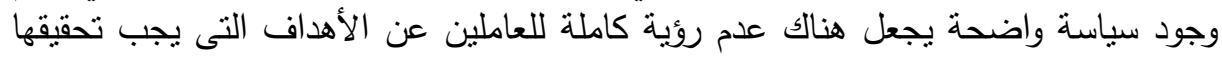

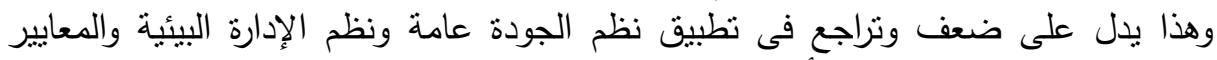

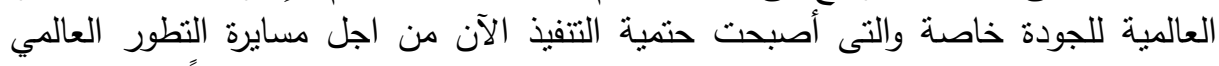

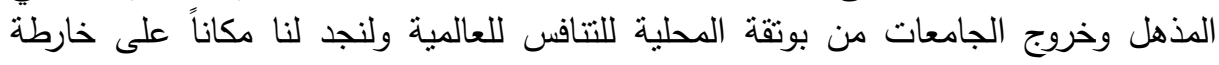

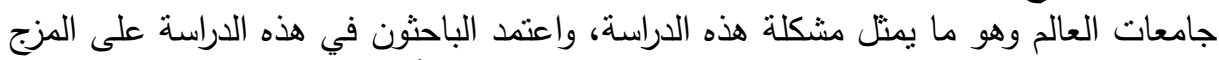

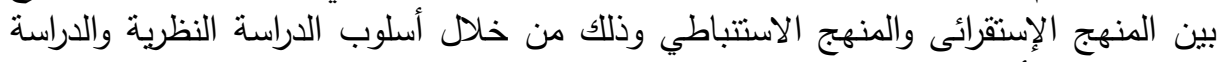

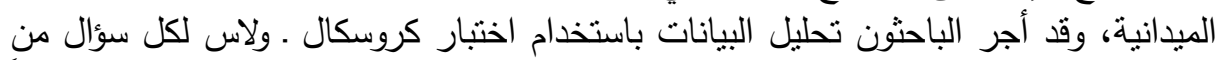

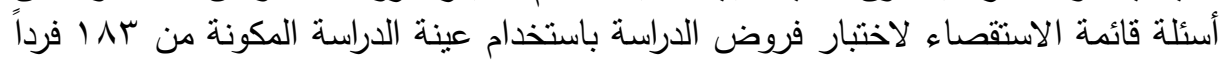

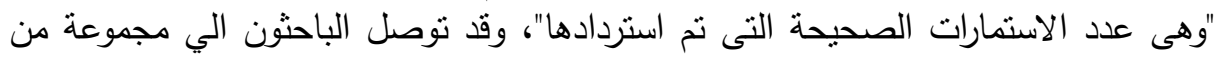

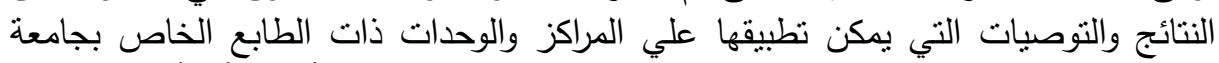

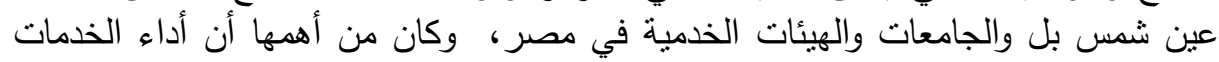

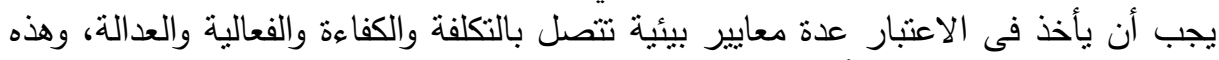

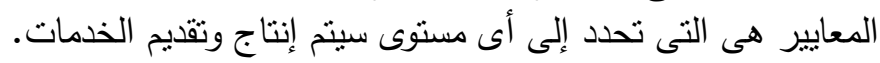




\section{Xas}

يتزايد حجم المتغيرات الاقتصادية والاجتماعية والسياسية بشكل سريع ومتلاحق يوما بعد أخر، ويصاحب هذه المتغيرات تقلم سريع في جميع المجالات سواء العلمية أو التكنولوجية،

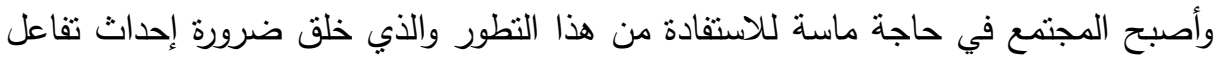
بين الجامعات بقدرتها الأكاديمية وبين المجتمع بمتطلباته المختلفة.

فلم يعد من الممكن اعنبار الجامعة مؤسسة تعليمية تعنى تخريج الكوادر والكفاءات في المجالات المختلفة فحسب، أو اعتبارها مجرد مراكز بحثية لإجراء البحوث الأكاديمية المتخصصة، فلم يعد من المكن أن تعيش أي جامعة بمعزل عن المجتمع المحيط بها بكل ما

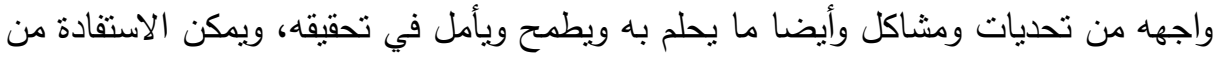
المعلومات التسويقية في تحسين جودة الخدمات وفقاً للمواصفات الفنية مع مراعاة الاعتبارات

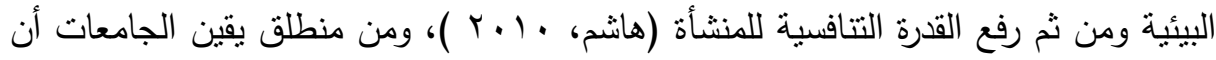
رسالتها وأهدافها أعمق وأنمل وان لها دور مجتمعي لا يمكنها التخلي عنه أو إغفاله وتجاهله

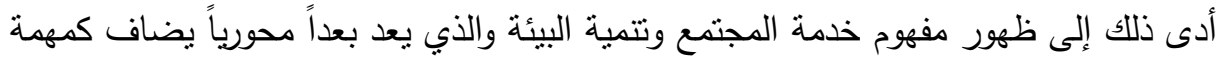
أساسية من المهام التي ينبخي أن تضطلع بها الجامعات، الأمر الذي أدى لسعى الجامعات الدئه

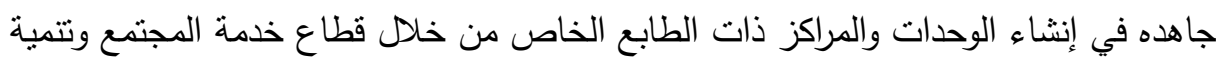

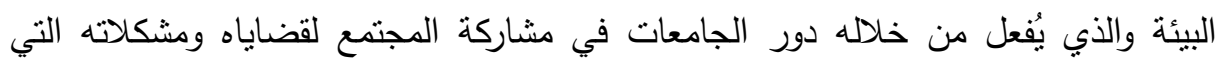

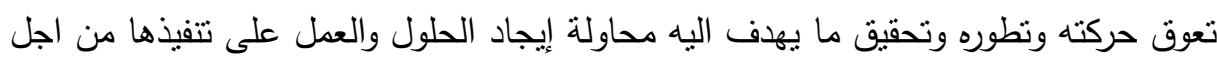

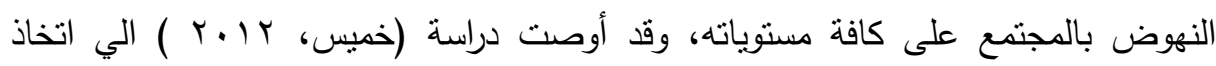
قرارات بتبني الأساليب الإدارية الحديثة منل نظام الإدارة البيئية 14001 ISO لتحسين وتطوير الأداء البيئي على المدى الطويل. وأوضح (Kotler and Armstrong,1994,640) بأن جودة الخدمة هي شكل من أشكال الطرائق التي تستخدمها المنظمة لتميز نفسها عن المنظمات الأخرى المشابهة لها في النثاط عن طريق تكوين صورة عن المنظمة تتحدد من خلالها شخصية المنظمة على جميع المستويات، ولقد كانت جامعة عين شمس سباقة دائما الى بلورة مفهوم خدمة المجتمع وتتمية

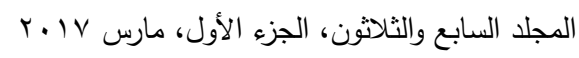


البيئة من خلال إنشاء المراكز والوحدات ذات الطابع الخاص سواء على مسنوى الجامعة او

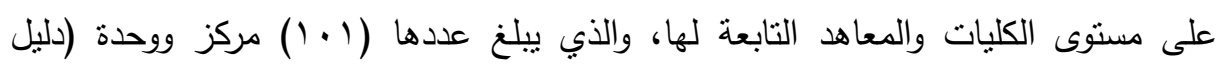

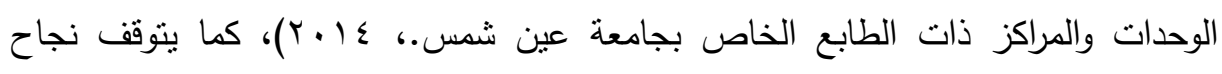

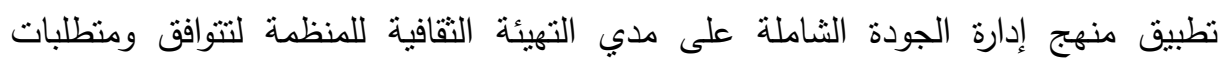
التطبيق الناجح والفعال للجودة، ذلك أن هذه الثقافة تعتبر قابلة للتعليم والتغيير والانتقال والتكيف، لذلك فمن المكن تغيير محتوي الثقافة لدي العاملين وغرس ثقافات جديدة للجودة

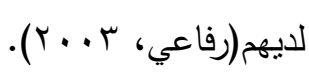

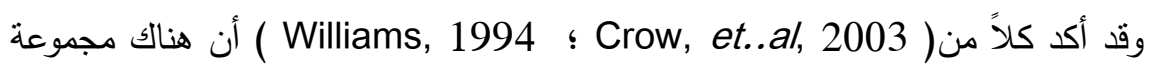
من العوامل المهمة والتي تؤثر في رضا العميل، وهي: توقعات العميل تجاه الخدمات المقدمة

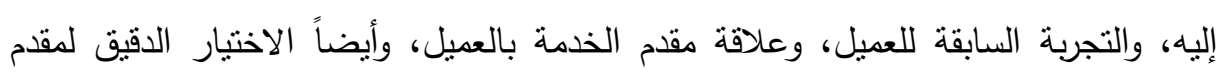
الخدمة، وتوصلت دراسة (عبدالرؤوف، بو99 1) الى مدى ارتباط الجامعة بالبيئية ومشكلاتها

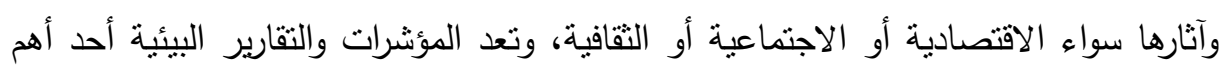

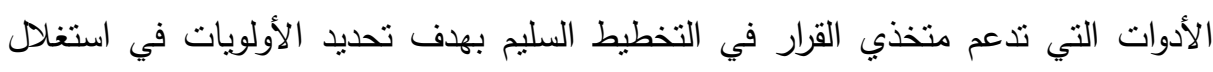

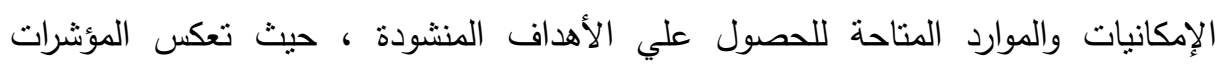

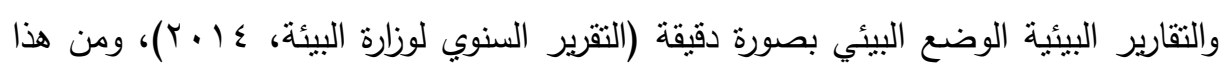

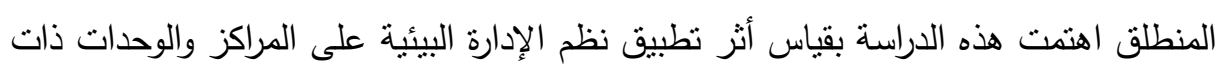
الطابع الخاص بجامعة عين شمس. ويجب على المنشآت ذات الأثر البيئي المساهمة مع دولها فى الحفاظ على البيئة، وقد

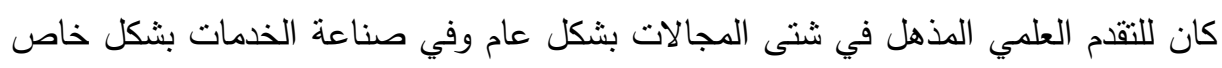

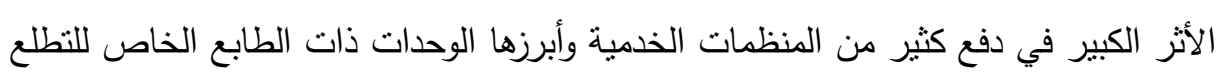
نحو استخدام أحدث منتجات التكنولوجيا في إنشاء هذه الوحدات المتخصصة وإدارتها، وكل

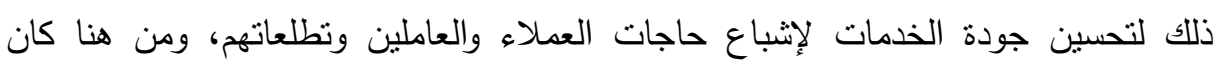

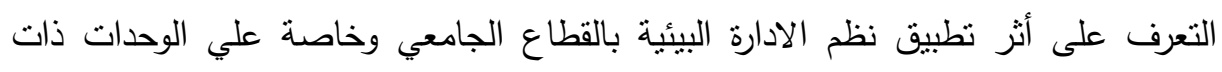
الطابع الخاص محور هذه الدراسة بهدف تعريف المختصين والمهتمين بأسس التسويق الفعال

$$
\text { للخدمات مع مراعاة البعد البيئي. }
$$

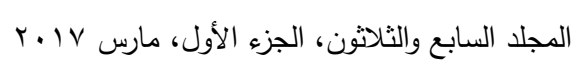




\section{and ILan}

على الرغم من وضوح مدى أهمية دور المراكز والوحدات ذات الطابع الخاص بالجامعة وكيف إنها أصبحت كحلقة وصل بين الجامعة والمجتمع الخارجي وإنها تمثل اليد اليمنى للجامعة والتي من شأنها تفعيل دور الجامعة في تننى ودراسة وتحليل القضايا المجتمعية والعمل على تقديم مساعدات وحلول لها وايضا دورها فى مجال البحث العلمي والأكاديمي. وربما يرجع ذلك إلى ان الوحدات والمراكز ذات الطابع الخاص منلها مثل باقى المنظمات التي على اختلاف أنواعها وتوجهاتها وأحجامها بسبب كثرة التغيرات البيئية من جهة وتداخل عناصر وعوامل ومنطلبات هذه البيئة من جهة أخرى نواجه جملة من التحديات والمشكلات والصعوبات فى مختلف المجالات، ويعتمد على قدرة وقابلية ادارة تلك المنظمات ونظام الأنشطة والعمليات فيها ومستوى كفاءتها وفاعليتها في التصدي والتعامل مع هذه

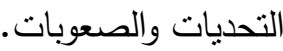
ومن أهم تللك التحديات بناء ثقافة تتظيمية وادارية داعمة لمواجهة ما تقابله من صعوبات لتحقيق أهدافها المنشودة، الأمر الذى ينطلب العمل على التحسين المستمر وتفعيل دور الثقافة التنظيمية ونظم الجودة ومواصفاتها المتتوعة ( 14000 ISO ) في مختلف ميادين العمل الإداري والإنتاجي والخدمي والتنسويقي والبيئي في هذه الوحدات والتى من شأنها الحفاظ على مائى بقاءها واعطائها قدره المنافسة باعتبارها من أهم التحديات التى فرضتها بيئة الإدارة الدولية. وباستعراض الدراسات السابقة ومنها دراسة (Padhy Et al., 2010) ودراسة

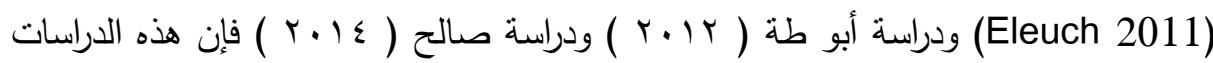

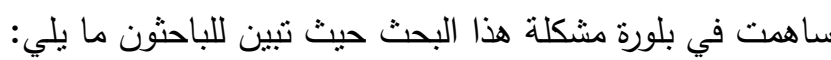

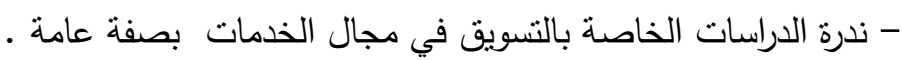

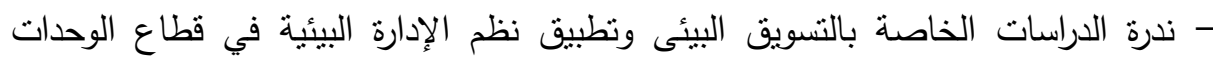

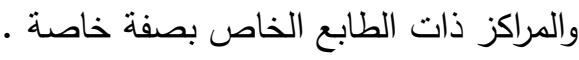


ولعل ما يعرقل مسيرة تلك الوحدات وأيضاً ما يواجهها من مشكلات تضارب

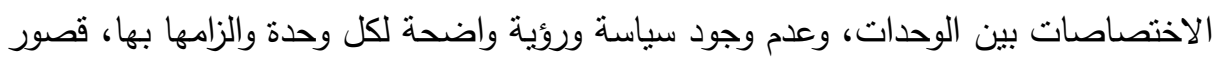

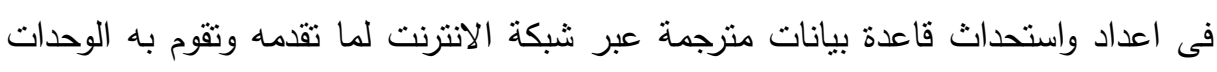
والتعريف بها محليا ودوليا، ضعف الجودة وعدم توظيف امكانيات وقدرات الافراد فى المكان الصحيح داخل العمل مما يهدر كم من الطاقات الغير مستغلة، عدم الرضا الكامل للعاملين

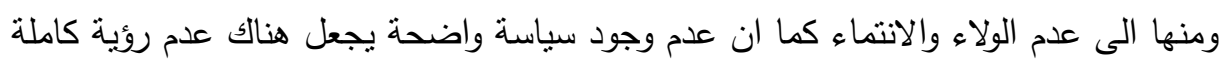

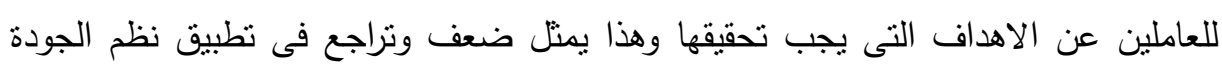

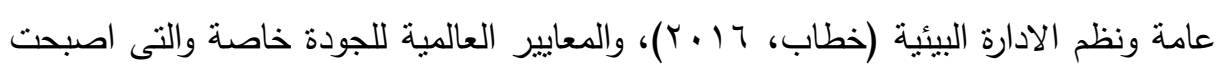
حتمية التتفيذ الان من اجل مجابهة التطور العالمي الدذهل وخروج الجامعات من بوتقة المحلية للنتافس للعالمية ولنجد مكاناً على خارطة جامعات العالم وهو ما يمثل مشكلة هذه وخه

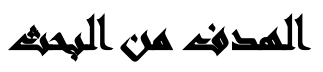

يهدف هذا البحث بشكل عام إلى دراسة واقع الخدمات بالمراكز والوحدات ذات الطابع

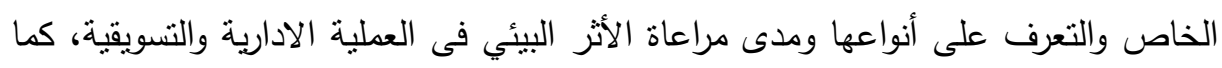
نذكر من أهدافه:

ا - التعرف على واقع نظم الادارة البيئية بالوحدات ذات الطابع الخاص عن طريق استطلاع اراء ووجهات نظر القيادات الادارية والعاملين فى تلك الوحدات.

r- التوصل الى ان هناك علاقة ارتباط موجبة بين تطبيق نظم الادارة ونظم الادارة الحديثة وبين تفعيل دور الوحدات ذات الطابع الخاص.

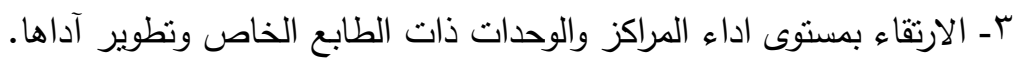

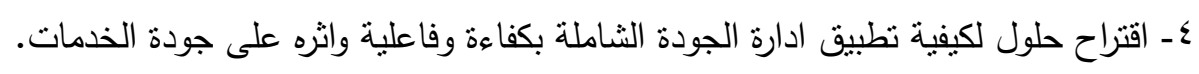
هـ استعراض الاتجاهات الحديثة فى مجال الادارة البيئية وجودة الخدمات وتسويقها ونتاج

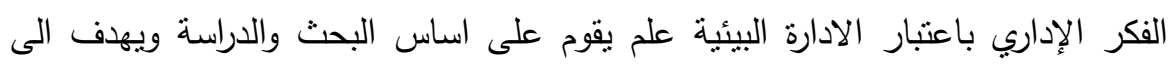
خلق تتظيم فعال وقادر على تجديد نفسه ويقوم على المشاركة.

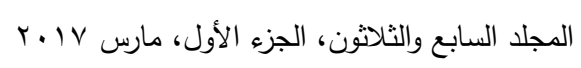




\section{أهمية المهميه}

تتمنل أهية هذا البحث في أنه نظراً للأهمية الاجتماعية والاقتصادية للمراكز والوحدات ذات الطابع الخاص وسعيها للنهوض بالعملية التعليمية والتدريبية فى الجامعة ومراكز البحوث وايضاً ما تسهم به في تخفيف العبء على موازنة الدولة وذلك من خلال تتمية الموارد الذاتية

مما ادى الى ضرورة الاهتمام بنظوير وتحسين وضع تلكك الوحدات وذلك بدراسة الشكلات التى تواجه الادارة والعاملين والتى تتسبب بدورها فى اعاقة مسيرتها فى اداء دورها،

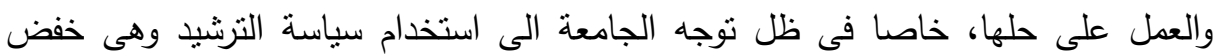

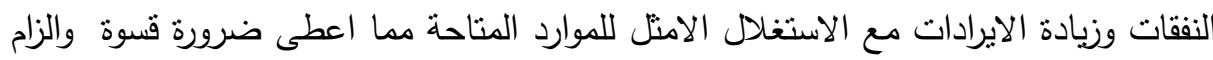
للاهتمام بنطبيق نظم الادارة البيئية والتى تمتل اداة محكمة لتصحيح اوضاع كل المنظمات التى تسعى لإثبات نفسها ككيان ناجح ومنافس قوى وذللك من خلال تقعيل سياستها فى تلاك الوحدات حتى يتسنى لها تحقيق اهدافها والتى من شأنها تعظيم قدرتها فى توفير موارد متجدد

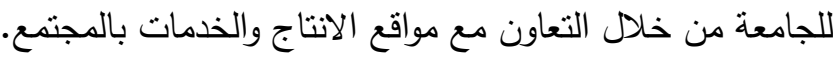

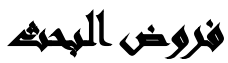

\section{تتمثل فروض البحث في النقاط التالية:}

ا. لا نوجد علاقة ذات دلالة بين تطبيق نظم الادارة البيئية واساليب الادارة الحديثة وزيادة كفاءة المراكز والوحدات ذات الطابع الخاص. r. لا نوجد علاقة ذات دلالة بين كفاءة النسويق وبين زيادة ايرادات المراكز والوحدات ذات دات الطابع الخاص. r. هناك علاقة ذات دلالة بين جودة الخدمة المقدمة وبين رضا العملاء والمستقيدين. 


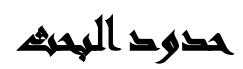

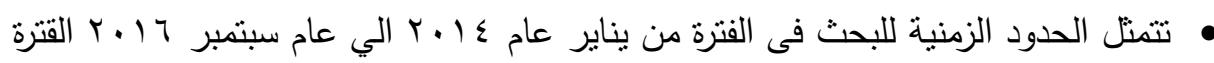

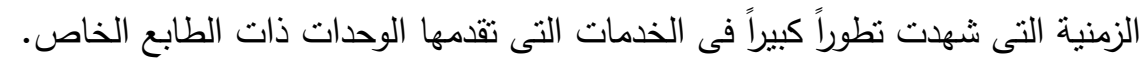

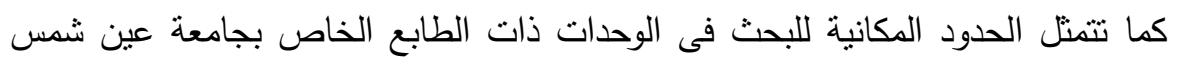
متضمنة منها الخدمية، الانتاجية، والتسويقية. ه الحدود العلمية والموضوعية : تركز الدراسة على قياس اثز تطبيق نظم الادارة البيئية ومدى فاعليتها على جودة الخدمات.

• ويرجع اختيار الباحثون للوحدات ذات الطابع الخاص بجامعة ودمات عين شمس إلى أنها تعد من

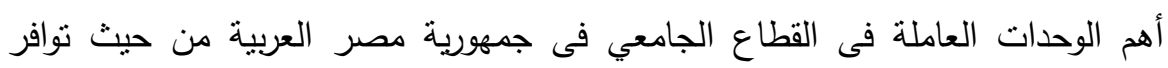
الإمكانات والكوادر الفنية والبشرية اللازمة والتى يمكن من خلالها تصدير الخدمة للخارج الخارج ووضع نموذج يحنذى به فى كافة المراكز الأخرى فى مصر .

\section{Andian}

اعتمد الباحثون في هذه الدراسة على المزج بين المنهج الإستقرائى والمنهج الاستتباطي

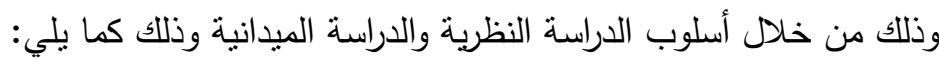
1- الاراسة النظرية(المنهج الوصفي): في هذا الإطار اعتمدت الدراسة على المنهج الوصفي بهدف استقراء جوانب المشكلة محل الدراسة، واستعراض وتحليل نتائج الدراسات السابقة معتمدةً في ذلك على المراجع والدوريات المهتمة بموضوع الدراسة، حيث قامت لتبن الدراسة بالتعرف على الجوانب المختلفة للمشكلة موضوع الدراسة، بالإضافة إلى الدراسات

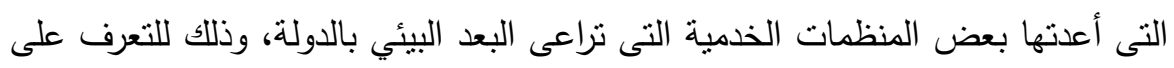

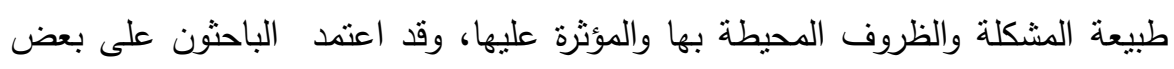

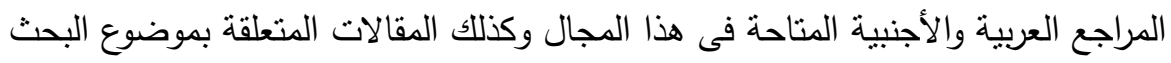
وإدارة الوحدات ذات الطابع الخاص المتخصصة بشكل عام وأثر تطبيق نظم الادارة البيئية 
r- الدراسة الميانية(المنهج التحليلي): عمد الباحثون في إجراء الدراسة الميدانية

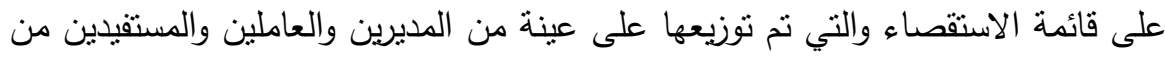

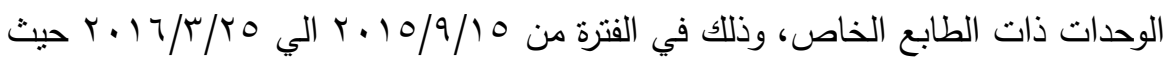
تم التعرف على أراءهم ورغباتهم واتجاهاتهم والعناصر الغير مرضية التى تواجهره

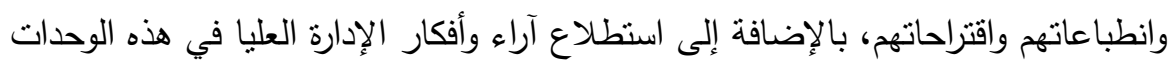
وقد تم استخدام الأساليب الإحصائية في تحليل البيانات والمعطيات التي تم جمعها.

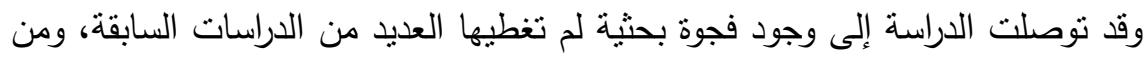
ثم اهتمت الدراسة بإجراء دراسة استكثافية في المجال التطبيقي، ثم تم استعراض نتائج الدراسة

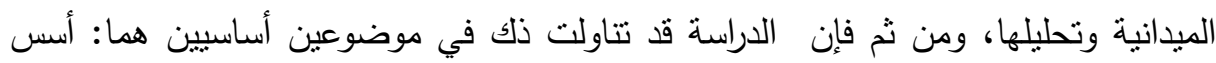

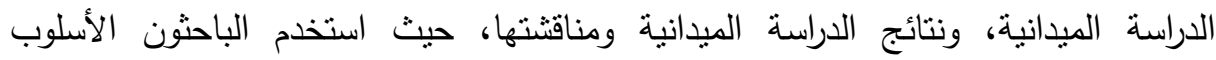
الإحصائي الأنسب للتحليل، وهو اختبار كروسكال ولاس، ولما كانت البيانات قد جاءت التهاته

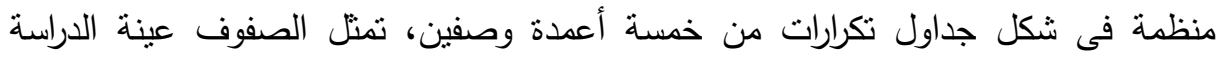
(المديرين والعاملين بالوحدات ذات الطابع الخاص، ومستقيدي وعملاء الوحدات) وتمثل

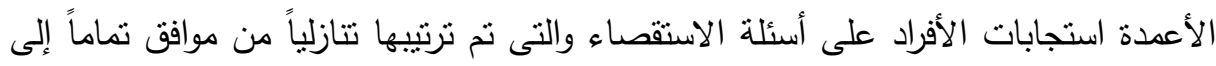
لا أوافق مطلقاً.

\section{أسلوب وأدوات الدراسة:}

أ- مجتمع الاراسة والعينة: بمكن نوضيح كلاً من مجتمع وعينة الدراسة كما يلي:

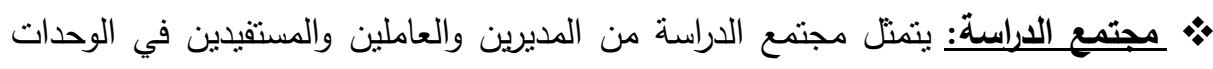

ذات الطابع الخاص بجامعة عين شمس متضمنة منها الخدمية، الانتاجية، والتسويقية.

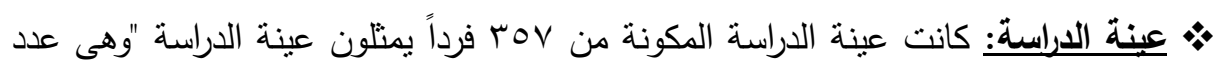

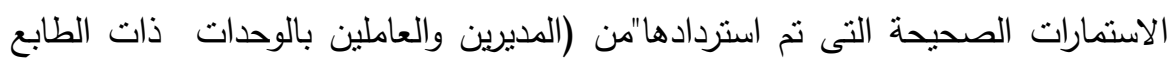


ونظراً لطبيعة البيانات التى تتسم بندرة الاستجابة على بعض فئات الاستجابة خاصة فئة

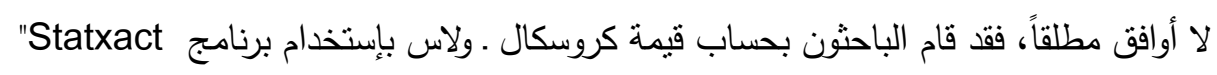

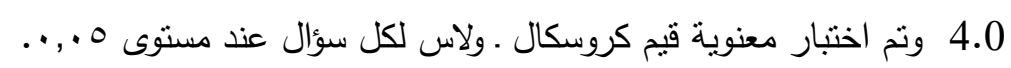

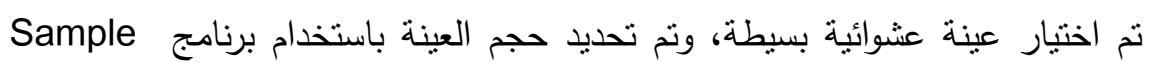
Size Calculator

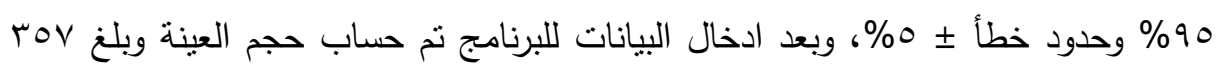
مفردة .

ب- قياس متغيرات الدراسة: في ضوء الدراسات السابقة التي إطلع عليها الباحثون، فقد اعتمد الباحثون فى قياس المتغير المستقل (نظم الادارة البيئية) والمتغير التابع (كفاءة المراكز

$$
\text { والوحدات ذات الطابع الخاص). }
$$

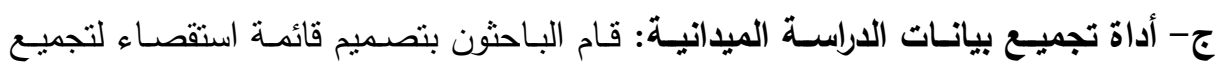
البيانات من مفردات البحث، حيث مر إعدادها وتصميمها بالخطوتين التاليتين:

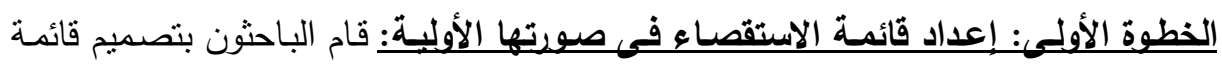

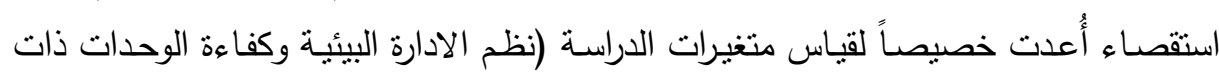

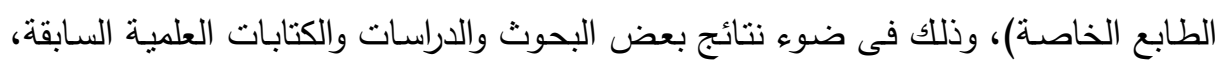
وكذللك فى ضوء ما كثفت عنه نتائج الدراسة الاسنطلاعية.

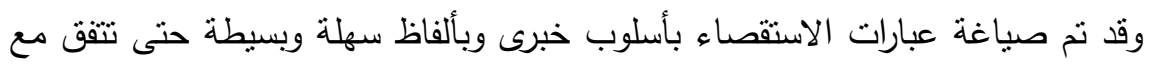
المسنوى الثقافي لبعض العاملين والمستفيدين بالمراكز موضع البحث، هذا وقد بلغ عدد هذه

$$
\text { العبارات تسعة وثلاثقن عبارة. }
$$

الخطوة الثانبة: اختبار صدق وثبـات الاستقصاء: قام الباحثون بإختبار قائمة الاستقصاء فى في صورتها المبدئية من خلال التعرف على صدقها وثباتها وذللك على النحو التالى:

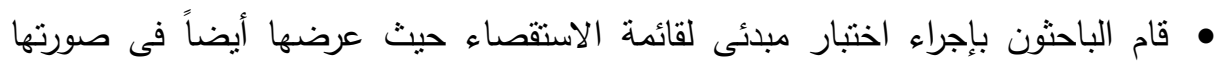

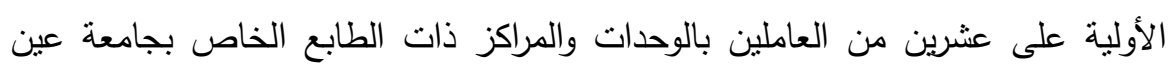

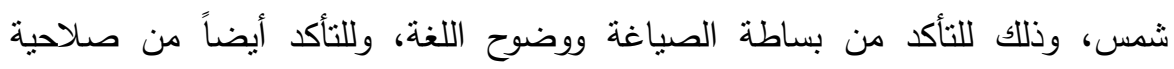

$$
\text { الاستقصاء من الناحية الميدانية. }
$$

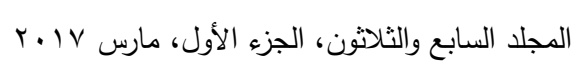


• تم إجراء اختبار ثبات للتأكد من إمكانية الاعتماد على نتائج البحث فى تعميم النتائج،

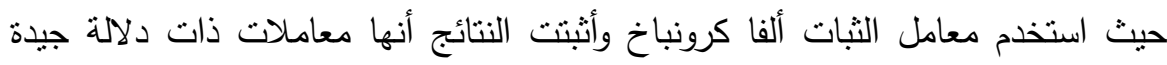
لتحقيق أهداف البحث، ويمكن الاعتماد عليها فى تعميم النتائج على مجتمع الدراسة.

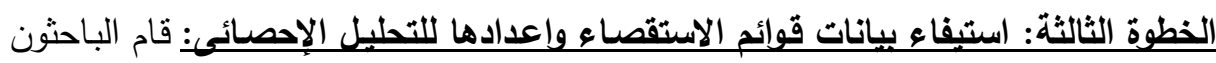
فى هذه المرحلة باستيفاء بيانات قوائم الاستقصاء من مفردات البحث بعد أن نم إعدادها فى لى

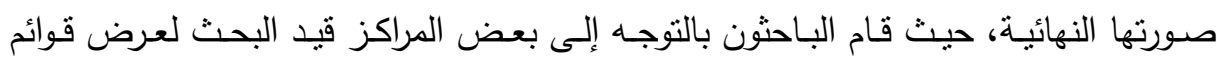
الاستقصاء على بعض العاملين والمستفيدين عن طريق المقابلات الثخصية التى أجراهـا

هذا كما تم مراجعة قوائم الاستقصاء بعد أن تمت الإجابة عليها، ثم قام الباحثون بإدخال

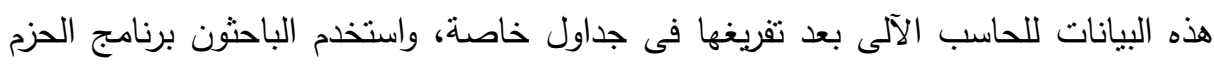
الإحصائية (SPSS) فى إجراء التحليل الإحصائى لبيانات الدراسة الميدانية. دـ أساليب التحليل الإحصائي: اعتمد الباحثون على الأساليب التالية:

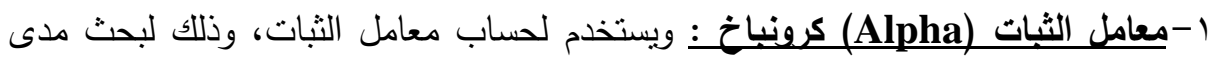
إمكانية الاعتماد على نتائج الدراسة الميدانية فى تعميم النتائج.

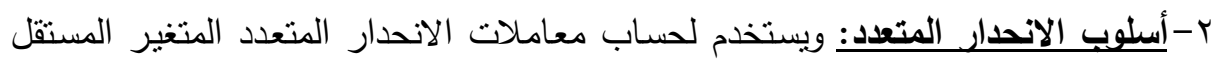

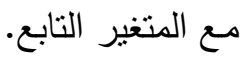
r-اختبار كروسكال ـ ولاس "Kruskal Walias Test" أحد الاختبارات اللامعلمية التي تستخدم لاختبار الفرق بين متوسطين. إن أنسب الاختبارات الإحصائية لهذا الشكل من البيانات هو اختبار كروسكال ـ ولاس لناس Kruskal Walias Test" القائل بعدم وجود فروف بين الصفوف الثلاثة (عينة الدراسة) فى استجاباتهم على أسئلة

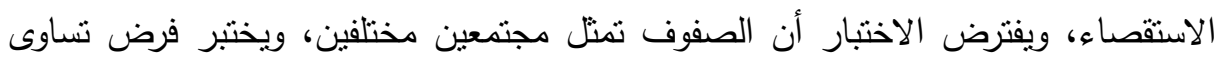

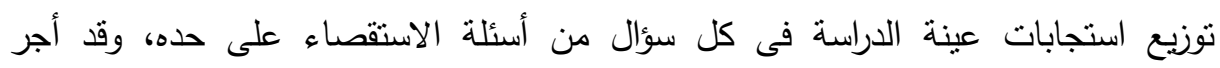


الباحثُن تحليل البيانات باستخدام اختبار كروسكال ـ ولاس لكل سؤال من أسئلة قائمة الاستقصاء لاختبار فروض الدراسة.

واستخدم الباحثّن برنامج الحزم الإحصائية (SPSS) فى إجراء التحليل الإحصائي لبيانات الدراسة الميدانية.

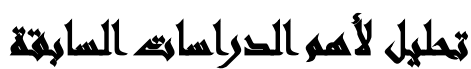

دراسة سلامه( \& 9 ( )): بعنوان: دراسة مقارنة للاتجاه البيئى فى بعض الجامعات

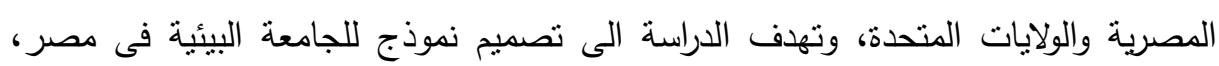

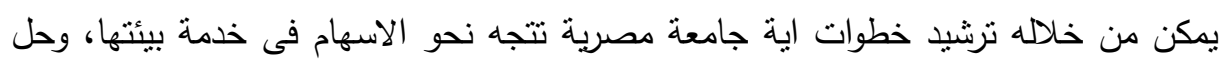
مشكلاتها وقد اتبع الباحث عدة خطوات لتحقيق هذا الهدف كمايلى: • • دراسة حالة الاتجاه بجامعة وسكونسن جرين الامريكية.

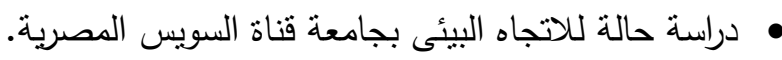

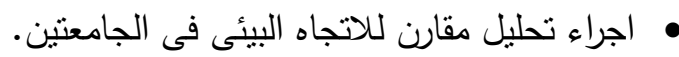

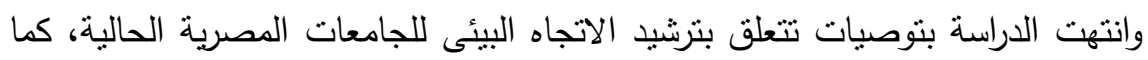

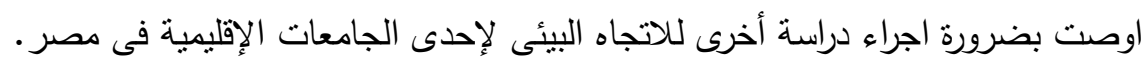

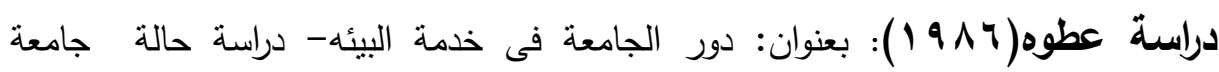
المنصورة، وقد قام الباحث بإجراء هذه الدراسة بهدف الوقوف على مدى إسهام جامعة

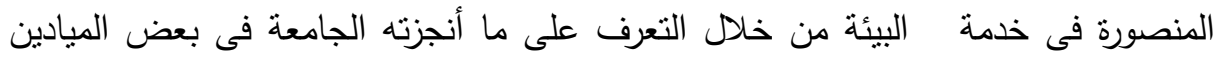
وهى :

• البرامج والمشروعات التى تخططها وتشرف على تتفيذها الكليات بهدف خدمة البيئة . • الوحدات ذات الطابع الخاص بالجامعة ويمثلها فى جامعة المنصورة محطة التجارب لتصني

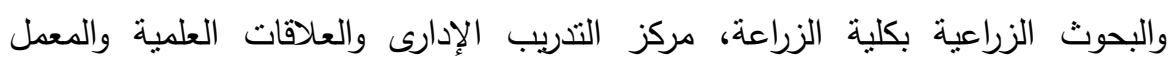

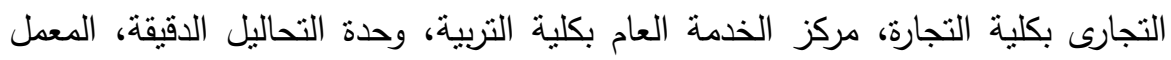

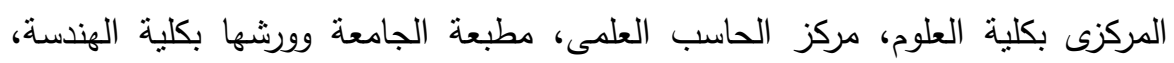

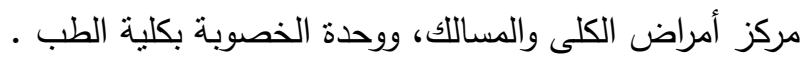

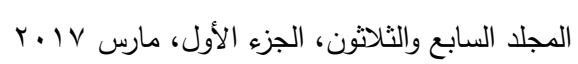


• البحوث التى تجرى فى الجامعة وربطها بواقع المجتمع ومشكلاته .

وقد اتبعت الاراسة المنهج الوصفى، المنهج التاريخى، وقد توصلت الدراسة إلى مجموعة

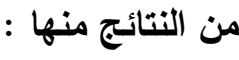
• عدم تحقيق كليتى التربية والزراعة للدور المنتظر منها فى مجال خدمة البيئة إلا أن كلية التربية تفوق كلية الزراعة في هذا المجال . • • مركز الخدمة العامة لا يحقق أهدافه. • محطة التجارب والبحوث الزراعية تحقق أهدافها فى مجال خدمة البيئة وإن كانت درجة التها

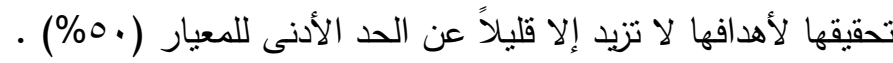

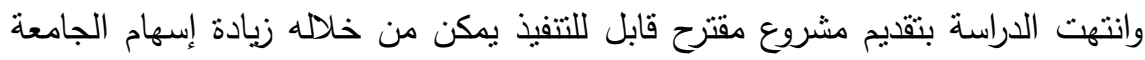
فى خدمة المجتمع وتطوير الوحدات ذات الطابع الخاص. وتتفق هذه الدراسة مع البحث الحالي فى تتاولها لدور الجامعة فى خدمة البيئة ودور

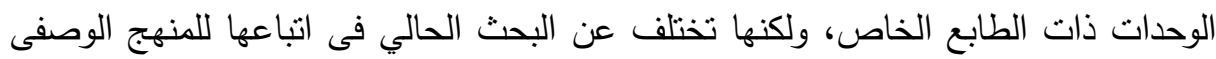
والتاريخى فقط ولم تعتمد على المنهج التطبيقى كما أنها نتاولت دراسة معظم كليات جامعة لبها المنصورة بعكس البحث الحالي الذى ركز على مراكز ووحدات جامعة عين شمس.

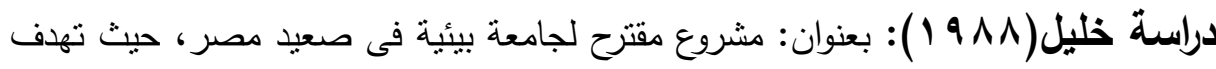
الدراسة الى التوصل الى نموذج مقترح لجامعة بيئية فى صعيد مصر لخدمة البيئة وقد انتهت الدراسة ببعض التوصبات منها قيام اعضاء هيئة التدريس بالتركيز على المشكلات البيئية، والاهتمام بالدراسات البيئية، وذلك عن طريق الدراسات الميدانية وطريقة حل المشكلات.

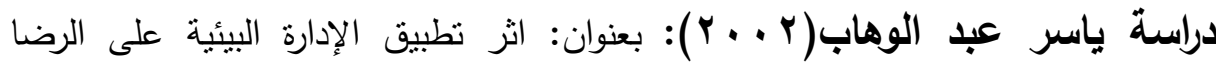

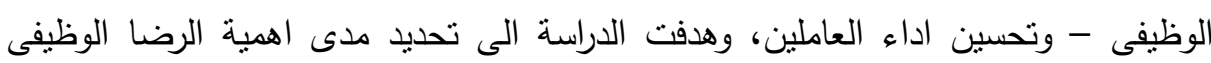

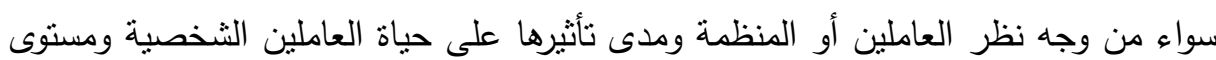

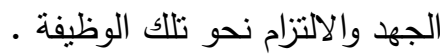




\section{وقد توصلت الدارسة الى مايلى:}

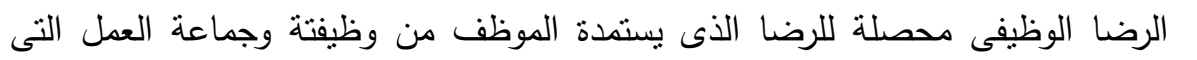

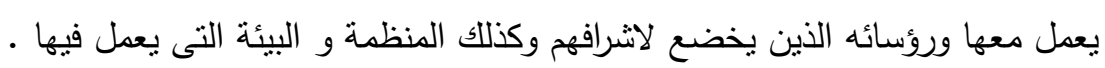

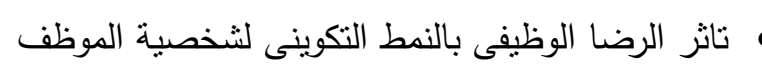

• الرضا يؤدى الى رفع مستوى الاداء والحوافز تدخل كمتغير وسيط بين الرضئ الأداء والرضا.

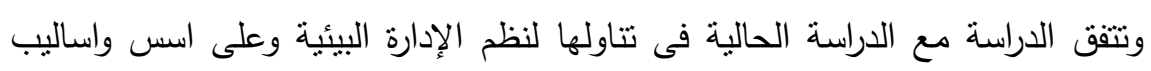

تطبيقها.

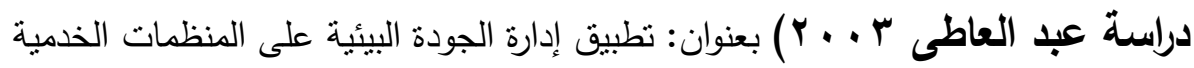

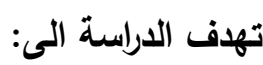

• تقيم الابعاد البيئية والإقتصادية والإجتماعية الناتجة عن غياب تطبيق نظم إدارة الجودة

البيئية بالمدن الجامعية.

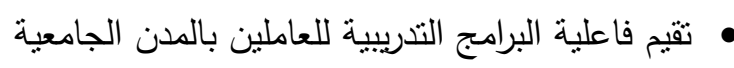
• • • اعداد نظام مقترح لنطبيق إدارة الجودة .

وقد توصلت الاراسة لعدة نتائج منها: عدم توافر امن وسلامة العاملين بالمطاعمكتوافر

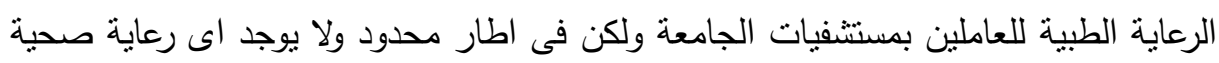
للعمالة المؤقتة .

واوصت الدراسة بوضع تصور مفترح لتطبيق نظم الإدارة البيئية وتتفق هذه الدراسة مع

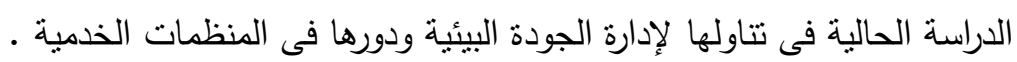

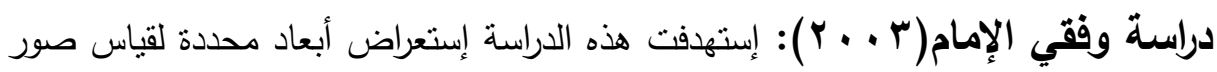
الخدمة المقدمة في المراكز الجامعية واثر توافر هذه المحددات على تحقيق رضا المستقبدين

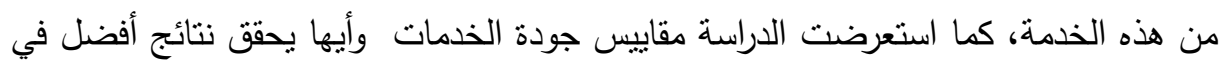
مجال قياس جودة الخدمات ـ كما هدفت الدراسة إلى التعرف على إدراك العوامل المحددة

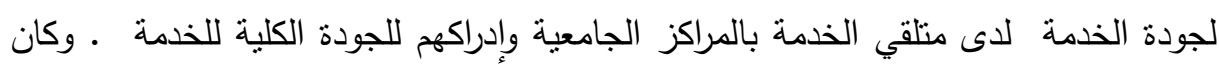

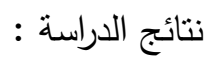


وجود خمسة محددات رئيسية تحتوى على 1 ا بعداً فرعياً يمكن استخدامها لقياس جودة

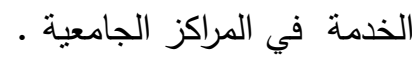
إثفاق الأهمية النسبية للمحددات مع الأهمية النسبية لذات المحددات بالنسبة لمنلقي

دراسة أبو طة(Y Y ب Y): هدفت هذه الدراسة إلى الكثف عن أثز الاضطراب البيئي كعامل مؤثز علي علاقة التوجة الاستراتيجي بالأداء التسويقي لشركات الاسكان بالعاصمة

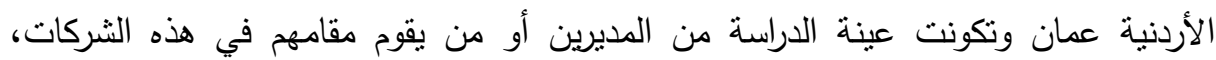

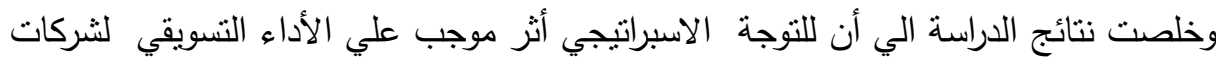

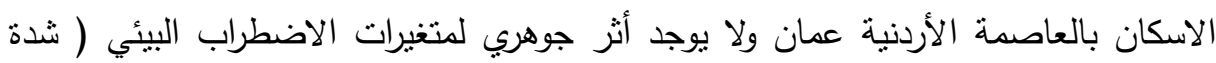

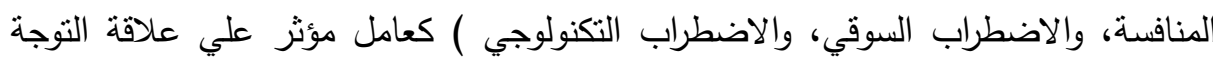
الاستراتيجي في حين أنة يوجد أثز ذو دلالة أحصائية علي الأداء التسويقي ( التكيف، التئل

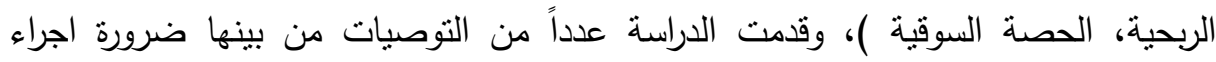
دراسات تبين الفرق بين الاضطراب البيئي وعدم التأكد البيئي من حيث مكونات كل منهما

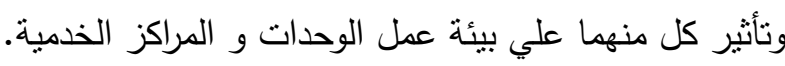

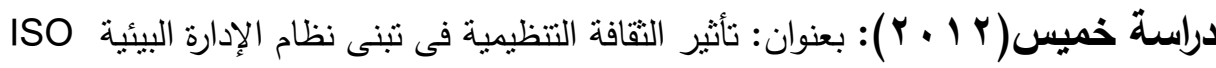
14001 دراسة تطبيقية فى الثركة العامة لصناعة الزجاج , وتهدف الدراسة الى مفهوم الثقافة التتظيمية ومكوناتها وأبعادها ، و نتخيص مستوى تطبيق المنظمة لمعايير نظم الإدارة البيئية ، وتحديد العوامل التى تقف وراء تحديد مستوى تبنى نظام الإدارة البيئية فى المنظمة.

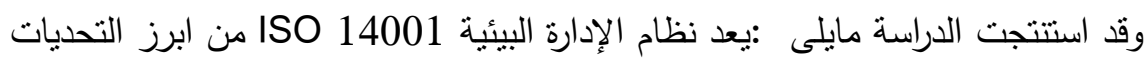

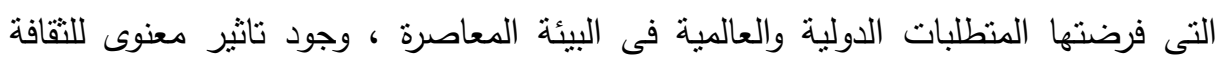

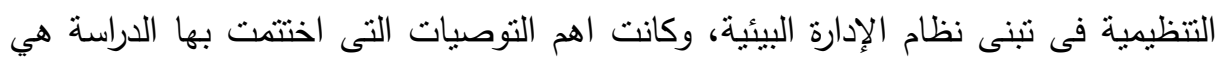

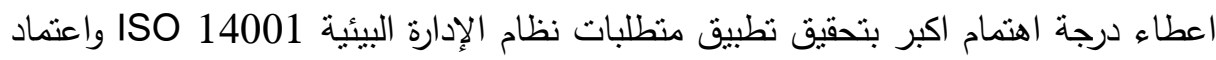
مبادئها بشكل دقيق،اتخاذ قرارات بتبنى الاساليب الإدارية الحديثة منل نظام الإدارة البيئية

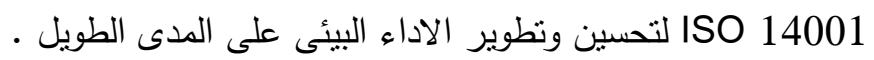


وقد اتفقت هذه الدراسة مع الدراسة الحالية فى مدى اهمية تطبيق نظم الإدارة البيئية فى

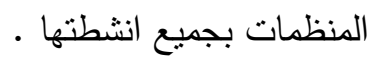

دراسة حمود وآخرون(Y Y Y Y): أجرى الباحثون دراسة بعنوان "أثز نظام المعلومات

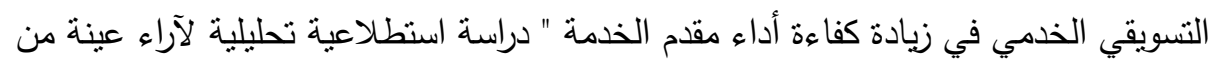
مقدمي الخدمة في مراكز بغداد، يهدف البحث الى توضيح مفهوم نظام المعلومات التسويقي

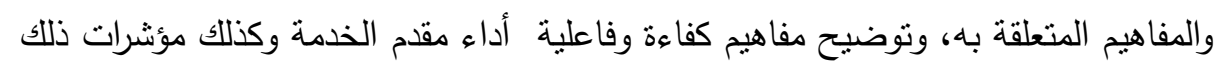
الأداء، وكذلك بيان الأثر الذي يحدثة وجود نظام للمعلومات التسويقية في زيادة كفاءة آداء

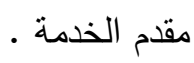

وقد سعت الدراسة إلى بيان أثز نظام المعلومات التسويقي الخدمي في زيادة كفاءة أداء

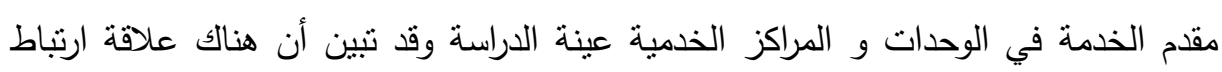

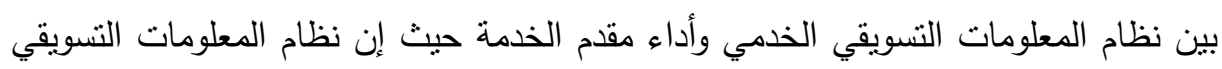
الخدمي يؤثر معنوياً على أداء مقدم الخدمة، وفي ضوء تحليل نتائج البحث توصلت الدئ الدراسة

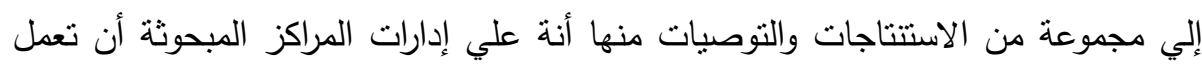
على الاهتمام بتفعيل نظام المعلومات التسويقي الخدمي لكونة يساهم في زيادة كفاءة أداء مقدم الخدات الخدمة ، لكونة هناك تأثنر واضح لنظام المعلومات التسويقي الخدمي في زيادة كفاءة أداء مقدم الخدمة . مانه

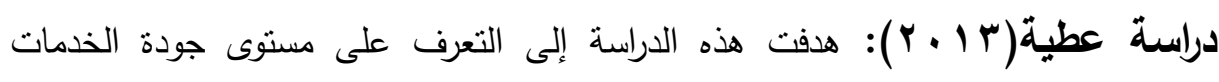
الفعلية المدركة من قبل العاملين والمستفبدين في المراكز العاملة في مدينة قلقيلية، ومعرفة

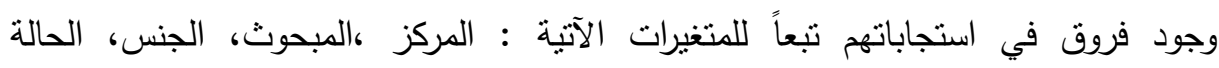

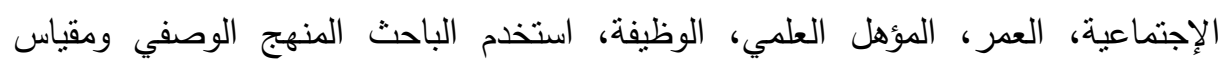

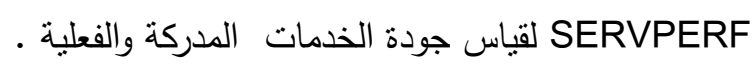
أظهرت الدراسة أن استجابات عينة الدراسة نحو قياس جودة الخدمات الفعلية والمدركة

من قبل العاملين والمستقيدين كانت عالية على مجالات الدراسة كافة وعلى الدرجة الكلية .

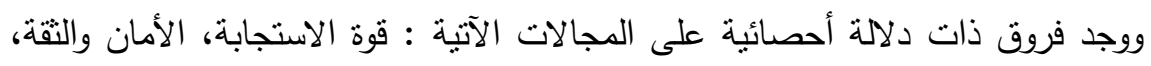

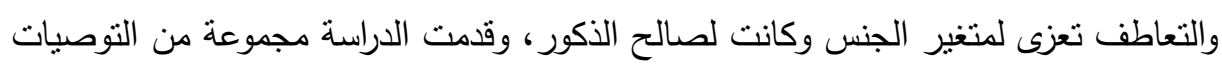

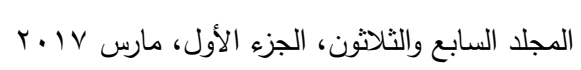


كان من ضمنها العمل على توفير مستلزمات المراكز سواء كان ذللك من الأجهزة أو المعدات الحديثة، وتوفير دورات تدريبية ملائمة للعاملين كل في مجاله من أجل تحسين جودة الخدمات المقدمة. دراسة صالح(ع ا • Y): قام الباحث باجراء بحث بعنوان "نماذج وطرق قياس جودة الخدمة"، هدفت هذه الدراسة إلى بناء واختبار مقياس خاص للجودة المدركة للخدمة ودرس

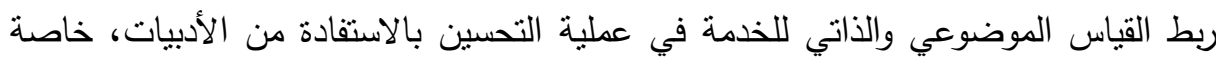

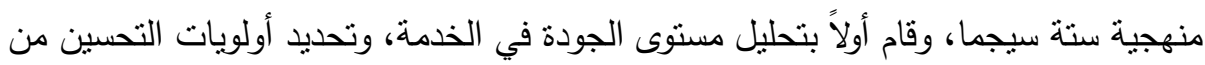
وجهة نظر العميل أي مجال الخدمة الأكثر تأثثراً على تقييمة والأضعف مستودى في في نظرها.

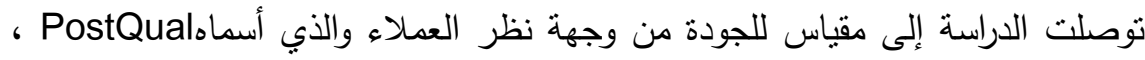
وإلى إظهار أن الأبعاد الثلاثة للجودة في هذا القطاع :الجودة الوظيفية، الجودة التقنية ومعالجة الثكاوى، وكذللك توصل البحث إلى ضرورة إعطاء الأولوية للجودة الوظيفية، لكونها الأكثر تأثيراً على تقييم العميل للخدمة.

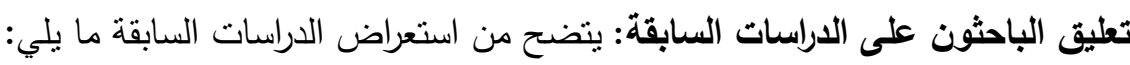

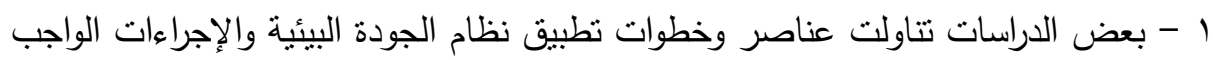
اتخاذها فى هذا الصدد.

r - بعض الدراسات قد ركزت على أهمية التسويق في مجال تقديم الخدمة .

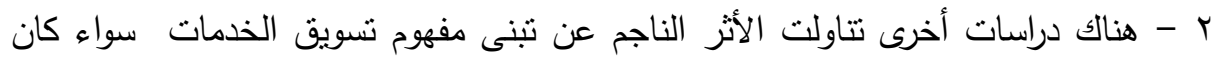
الأثز إيجابيا أم سلبيا. ومما لاشك فيه أن هذه الدراسات قد ساهمت في بلورة مشكلة هذا البحث حيث أنة

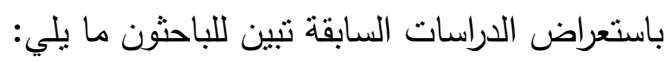

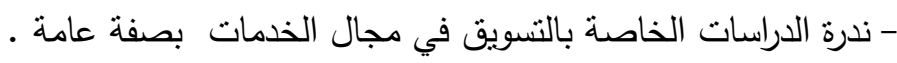

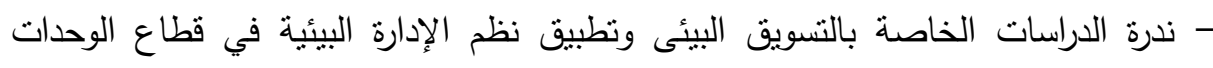

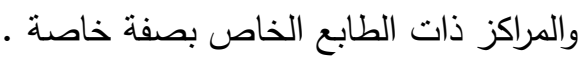


كما يميز هذه الدراسة عن الدراسات السابقة:

1- قياس جودة الخدمات من وجهة نظر المستقيدين والعاملين، وفي الدراسات السابقة جزء قليل استخدم هذا المقياس، وتتفق مع بعض الدراسات بأنها طبقت على ولى العاملين

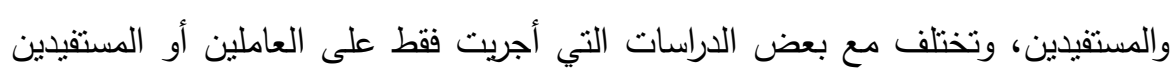

فقط.

ץ- مكان الدراسة مختلف عن كل الدراسات السابقة حيث كان المراكز والوحدات ذات الطابع

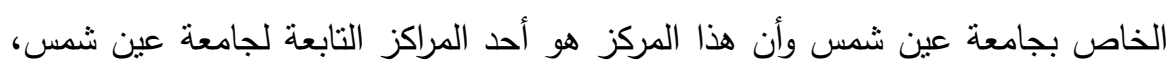

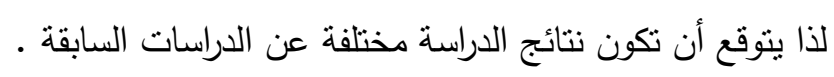

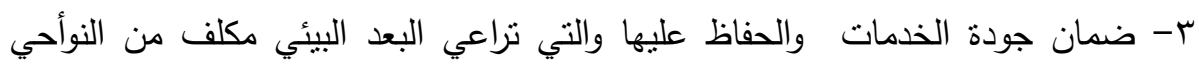

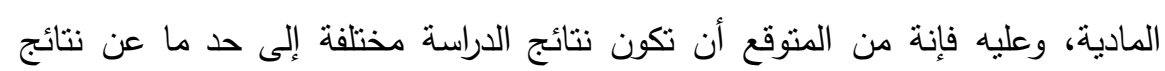

$$
\text { الدراسات السابقة. }
$$

ويتضح من عرض الدراسات السابقة للموضوع، أن هذه الدراسة مكملة لما ورد في تلك إلكان

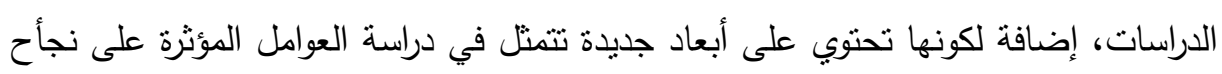

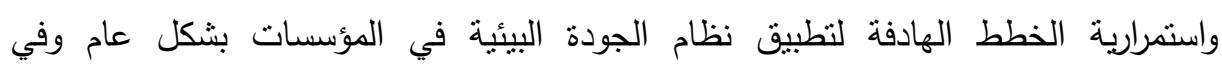

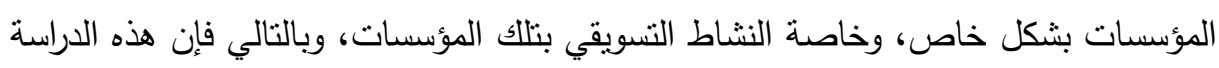

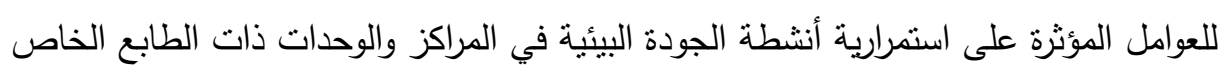
بجامعة عين شمس وقياس تأثثر ذلك علي تسويق الخدمة بهذه المراكز ولربما نساهم في إثراء هذا الحقل العلمي الهام بمشيئة اله. لذا يحاول الباحثنون من خلال هذه الدراسة الكثف عن الممارسات الخاصة بذلك المفهوم

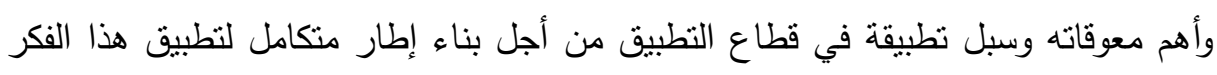

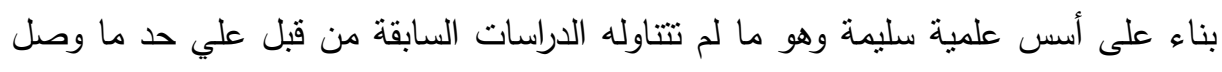

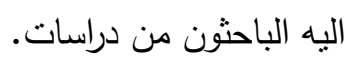

وستحاول هذه الدراسة الاستفادة من نقاط القوة في الدراسات السابقة ومحاولة نطويرها

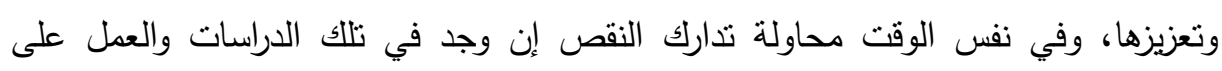

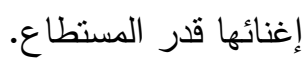

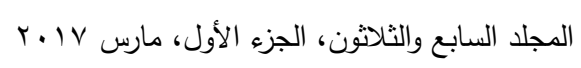


وتستعرض الدراسة فيما يلى نتائج التحليل الإحصائي لكل سؤال من أسئلة الاستقصاء

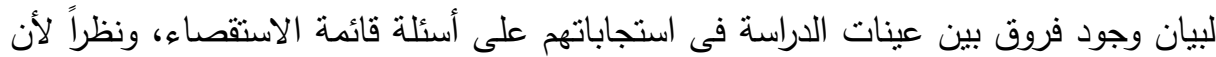
هناك مستويان لعينة الدراسة يراد اختبار فروض الدراسة عندها، فإن هناك درجتان للحرية يتم اختبار وجود الفروق بين المجموعتين عندها.

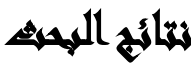

الفرض الأول: لا توجد علاقة ذات دلالة بين تطبيق نظم الادارة البيئية وإساليب الادارة

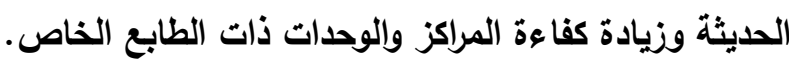

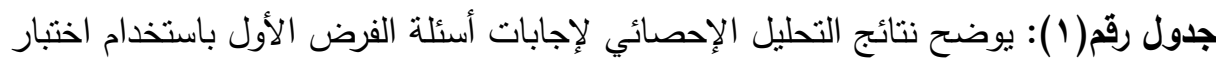

\begin{tabular}{|c|c|c|c|c|c|}
\hline 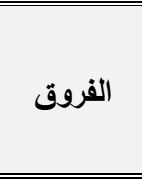 & الدالة الدالة & 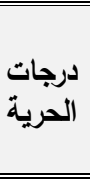 & كروسكال & 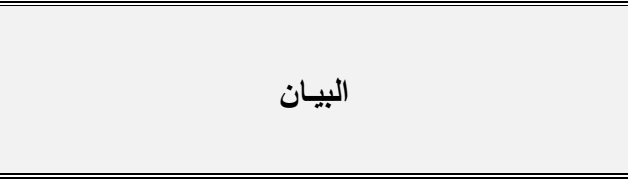 & b \\
\hline غير معنوي & $\cdot, 1 \leq$ & r & r,q & 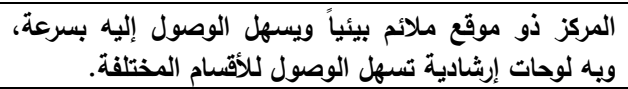 & 1 \\
\hline معنوي & $\cdot, \cdot 1$ & r & $9,1 \leq \leqslant$ & الأتنظام بالمركز مرنبة ويسهة الوصول إليها، وأماكن & r \\
\hline معنوي &., .0 & $r$ & $0,9 \cdot 0$ & المركز مجهز تماما بأحدث الأجهزة. & $r$ \\
\hline غير معنوي & $\cdot, r r$ & r & $r, r \wedge \varepsilon$ & بذلكما يلتزم المركز بتقايم خدمة فى وقت محدد فأنه يلتزم & $\varepsilon$ \\
\hline غير معنوي & $\cdot, 14$ & r & $\varepsilon, .0 r$ & لعلها. توجهني مشكلة فان المركز ببدى التماماً خاصة & $\bullet$ \\
\hline غير معنوي & $\cdot, r_{0}$ & $r$ & $r, \vee \vee Y$ & يؤدى المركز خدماته بطريقة صحيحة بيئياً ومن أول مرة. & 7 \\
\hline غير معنوي & $\cdot, 11$ & $r$ & $r, \leqslant \leqslant$. & أضع ثثتي الكاملة في الإدارة والفنيين والعاملين بالمركز . & $\mathrm{V}$ \\
\hline غير معنوي & $\cdot, 94$ & r & $\cdot$, Y & بالأدان في التعامل الخلق لاى العركز. & $\wedge$ \\
\hline معنوي & $\cdot, \cdot \varepsilon$ & $r$ & $7,1 \wedge 9$ & يتابع العاملون المركز حالة المنتفع بصفة مستمرة. & 9 \\
\hline 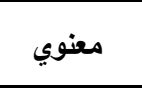 & $\cdot, \cdot r$ & r & V,rqr & 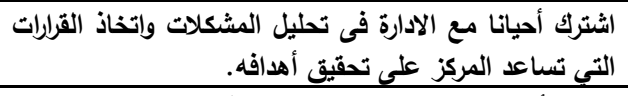 & 1. \\
\hline معنوي & $\cdot, \ldots$ & $r$ & $1 \cdot, 7 \mathrm{r}$. & اشعر بأن مواعيد العمل بالمركز مناسبة. & 11 \\
\hline غير معنوي & r & r & $\cdot, q \leq r$ & تقنوم عادة إدارة المركز حوافز تثجيعية للعاملين الذين & ir \\
\hline غير معنوي & $\cdot, 09$ & $r$ & $1, \cdot \leq 9$ & في وظيفتي رئيسي المباشر على ان اعرف نتيجة مستوى ادائى & $1 \pi$ \\
\hline
\end{tabular}

404

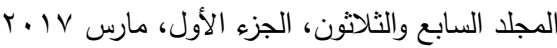


تحليل نتائج إجابات الفرض الأول: يتضح من العرض السابق عدم وجود فروق معنوية بين

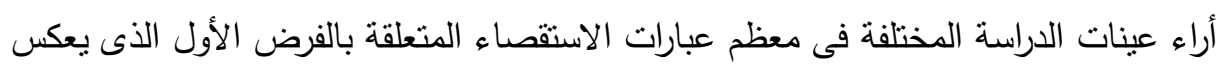

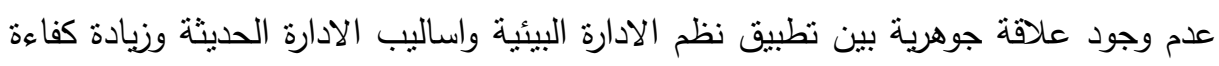

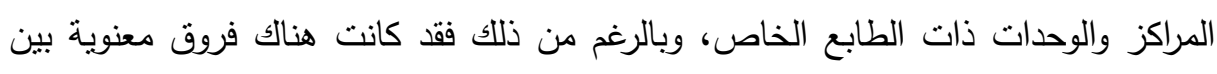

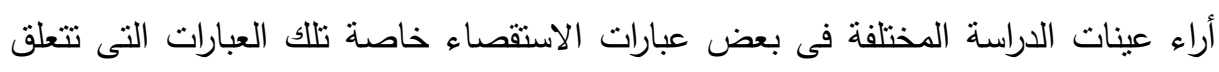

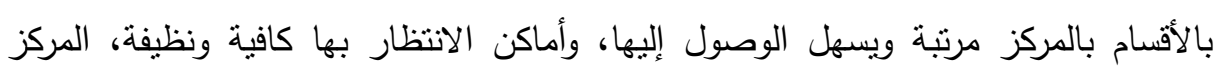

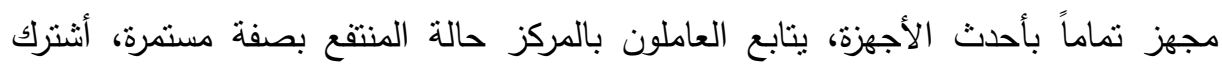

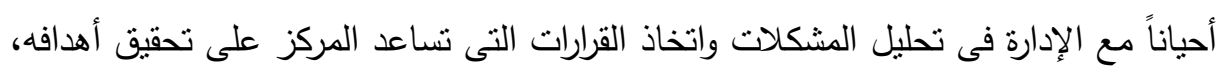

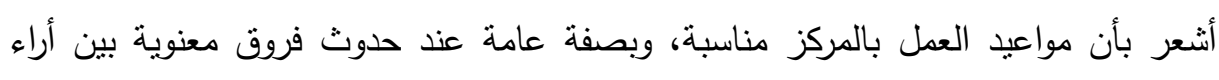

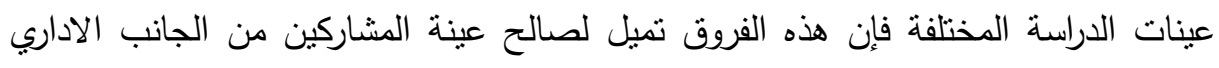

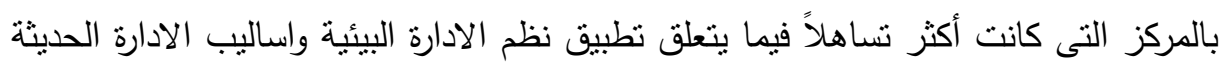
وزيادة كفاءة المراكز والوحدات ذات الطابع الخاص. 
الفرض الثاني: لا توجد علاقة ذات دلالة بين كفاءة التسويق وبين زيادة ايرادات المراكز والوحدات ذات الطابع الخاص: جدول رقم(ץ) يوضح نتائج التحليل الإحصائي لإجابات أسئلة الفرض الثاني باستخدام اختبار

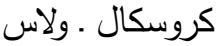

\begin{tabular}{|c|c|c|c|c|c|}
\hline الفروق الفرق & الالالة & 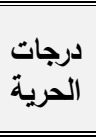 & كروسة اختبار & 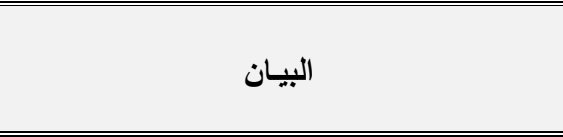 & م \\
\hline غير معنوي & $\cdot, 11$ & $r$ & $\varepsilon, \leqslant$ q & 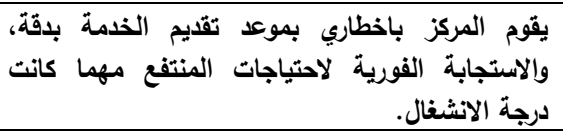 & 1 \\
\hline غير معنوي & $\cdot, \leqslant V$ & $r$ & $1, \wedge 04$ & 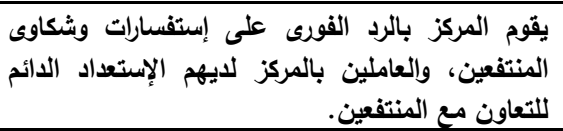 & r \\
\hline غير معنوي & $\cdot, r r$ & $r$ & $r, Y \leq r$ & 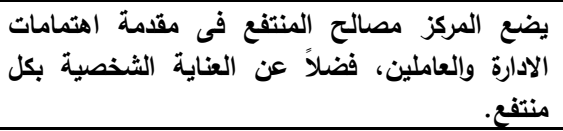 & $r$ \\
\hline غير معنوي & $\cdot, r r$ & $r$ & $r, r \leq$. & سقاعات العمل والوقت المخصص لمن للخدمة بدقة. معه، وملائمة & $\varepsilon$ \\
\hline غير معنوي & $\cdot,+4$ & r & $0, \varepsilon \cdot 7$ & 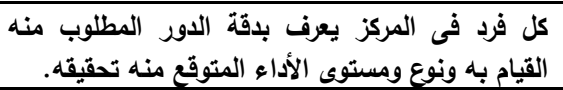 & 0 \\
\hline غير معنوي & $\cdot, \cdot 1$ & $r$ & $\wedge, \cdot \wedge 1$ & 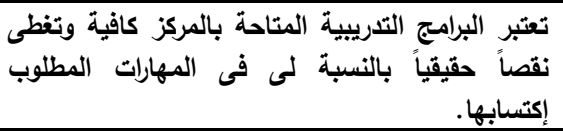 & 9 \\
\hline غير معنوي & $\cdot, \leqslant 0$ & r & 1,71 & 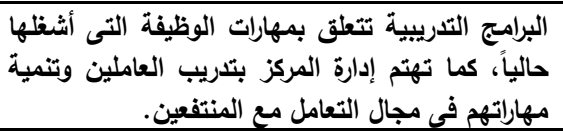 & $\checkmark$ \\
\hline غير معنوي & $\cdot, \infty$ & r & 0,911 & إستثمار وليس تكلفة. أنوير معرفة ومهارات العاملين بها & $\wedge$ \\
\hline غير معنوي & $\cdot, \leqslant 1$ & $r$ & r,va. & للعاملين ايرادات المركز تعتمد علي الكفاءة التسويقية & 9 \\
\hline غير معنوي & $\cdot, 01$ & $r$ & $1,9$. & 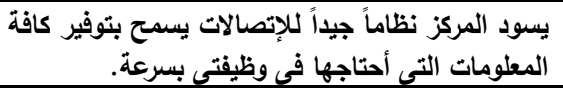 & 1. \\
\hline غير معنوي & $\cdot, \wedge 9$ & r & $\cdot$, rry & تهتم إدارة المركز بالتركيز على البعد البيئي بالمركز. & 11 \\
\hline غير معنوي & $\cdot, r \wedge$ & r & $1,9 \wedge 1$ & 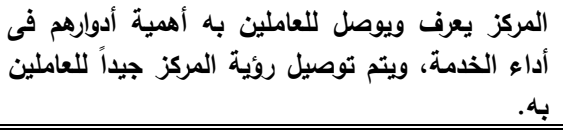 & ir \\
\hline
\end{tabular}


تحليل نتائج إجابات الفرض الثاني: يتضح من العرض السابق عدم وجود فروق معنوية بين

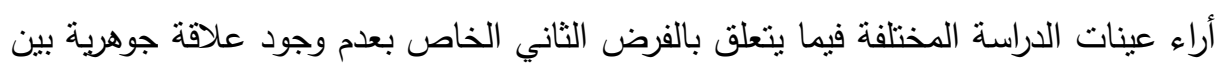

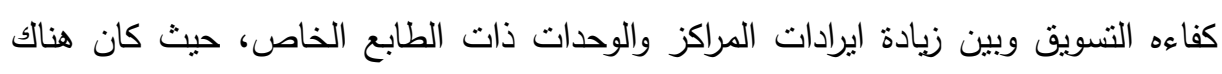

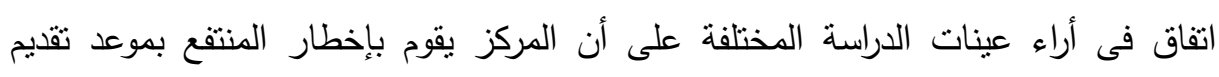
الخدمة بدقة، الاستجابة الفورية لاحتباجات المنتفع مهما كانت درجة الانشغال، ويقوم المركز

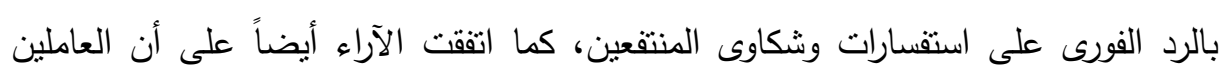

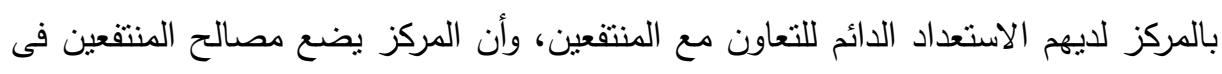

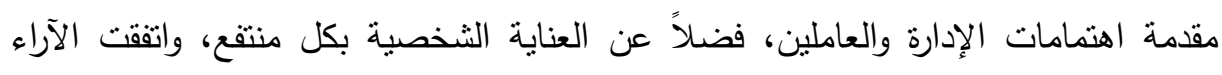

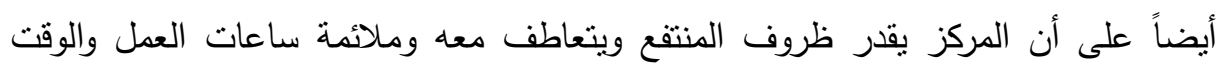
المخصص للخدمة بدقة، وأن كل فرد فى المركز يعرف بدقة الدور المطلوب منه القيام به

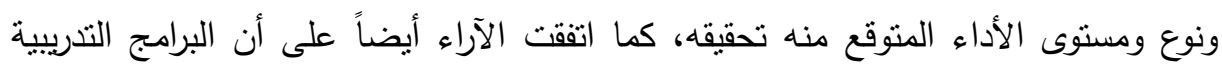

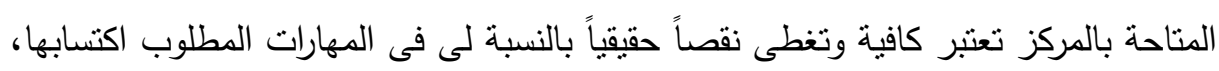

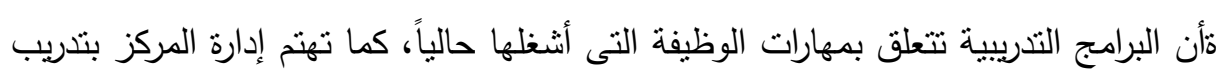

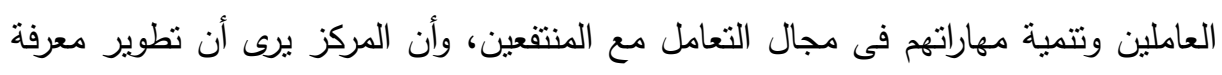

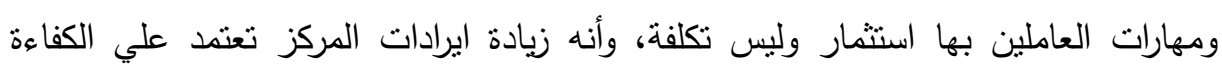

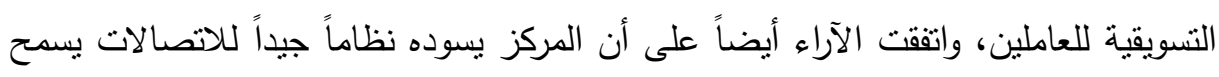
بتوفير كافة المعلومات التى يحتاجها الموظف فى وظيفته بسرعة، وأن إدارة المركز يهتم بالتركيز على البعد البيئي بالمركز ، المركز يعرف ويوصل للعاملين به أهمية أدوارهم فى أداء

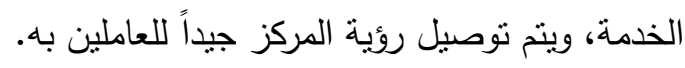

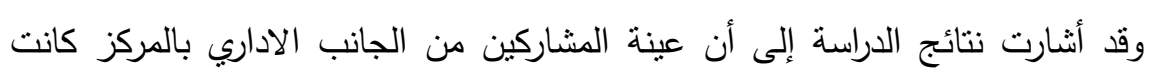

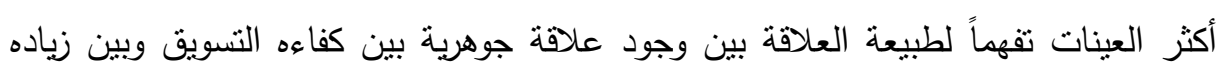

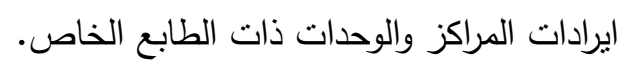


الفرض الثالث: هناك علاقة ذات دلالة بين جودة الخدمة المقدمة وبين رضا العملاء والمستفيدين. جدول رقم(ץ): يوضح نتائج التحليل الإحصائي لإجابات أسئلة الفرض الثالث باستخدام اختبار كروسكال .ولاس

\begin{tabular}{|c|c|c|c|c|c|}
\hline 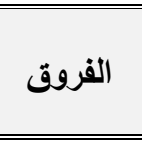 & الالالة & 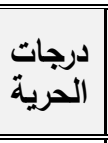 & اختباركروسكاة & 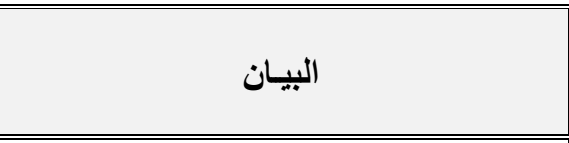 & م \\
\hline غير معنوي & $\cdot, \wedge \varepsilon$ & r & $\cdot, V Y V$ & تهنت إدارة المركز بالتعرف على رأيك في جودة الخذمة & 1 \\
\hline غير معنوي & $\cdot, \cdot 9$ & r & •, Yצד & يتم تنفيذها في المكانة سياسة مكتوبة عن بيئة خالية من التنخين & r \\
\hline غير معنوي & 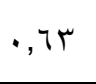 & r & $1, \wedge 97$ & ومناحة. & r \\
\hline 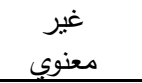 & $\cdot, 7 \varepsilon$ & r & $r, 191$ & 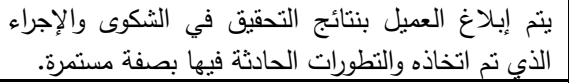 & $\varepsilon$ \\
\hline غير معنوي & $\cdot, 01$ & r & $1, \wedge \vee r$ & ينت تثقيف وتدريب العاملين في المركز علي المخاطر & 0 \\
\hline 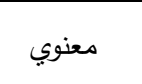 & $\cdot, \cdot r$ & $r$ & $\vee, \wedge \circ \leq$ & 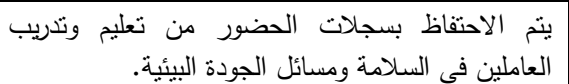 & 7 \\
\hline غير معنوي & $\cdot, 1 T$ & r & $r, 979$ & يحدد المركز لجنة و أو وحدة السلامة والصحة المهنية والبيئة. & $\mathrm{V}$ \\
\hline غير معنوي & $\cdot, 71$ & r & $r, 19$ & القيام بالتصميح والتحريث الاعتبار سلامة وصناء والصيانة. البيئة أثناء & $\wedge$ \\
\hline غير معنوي & $\cdot, 1 \mathrm{r}$ & r & $\varepsilon, Y \vee\urcorner$ & 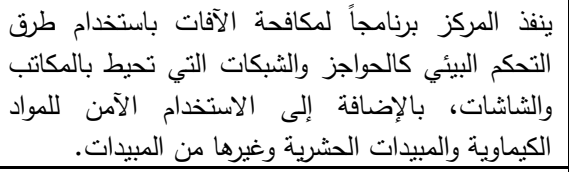 & 9 \\
\hline غير معنوي & $\cdot, 0$ & r & $1,1 \leq$ & 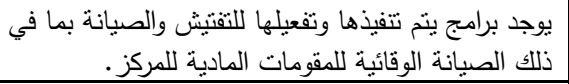 & 1. \\
\hline غير معنوي & $\cdot, r_{1}$ & r & r, YOr & 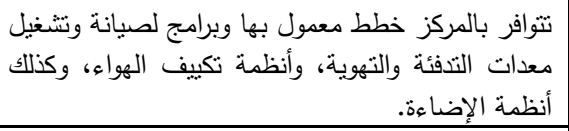 & 11 \\
\hline غير معنوي & $\cdot, 0 \wedge$ & $r$ & $1, \varepsilon \cdot 7$ & توجد خطة يتم تتفيذها للإدارة الآمنة للنفايات. & IT \\
\hline غير معنوي & $\cdot, 0$ r & $r$ & r, rדr & 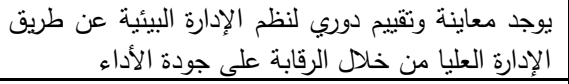 & 14 \\
\hline غير معنوي & $\cdot, 7)$ & $r$ & $r, 19$. & يساعد وجود نظام لإدارة الجودة الثاملة في تطبيق نظم & $1 \varepsilon$ \\
\hline
\end{tabular}


تحليل نتائج إجابات الفرض الثالث: ينضح من العرض السابق عدم وجود فروق معنوية بين

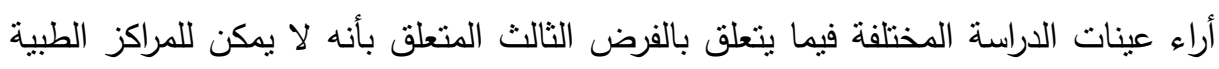

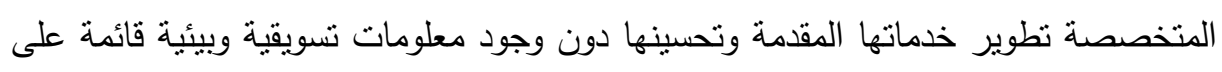

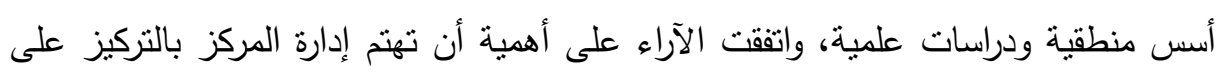

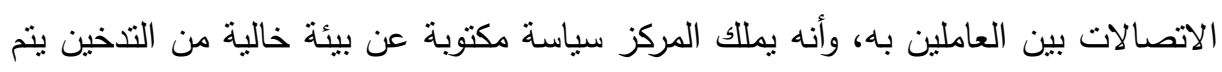

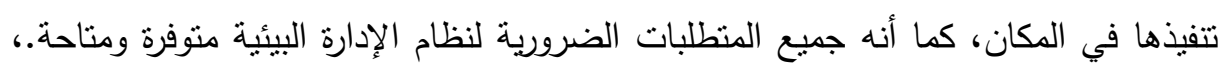
وأنه يتن إبلاغ العميل بنتائج التحقيق فى الثكوى والإجراء الذى نم اتخاذه والتطورات الحادثة

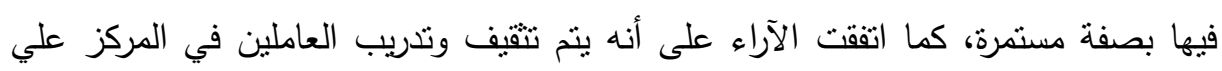

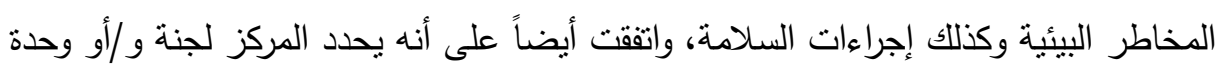
السلامة والصحة المهنية والبيئة، ويأخذ المركز بعين الاعتبار سلامة وصحة البيئة أثناء القيام

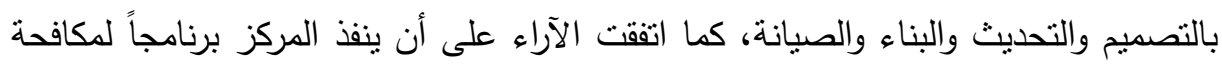

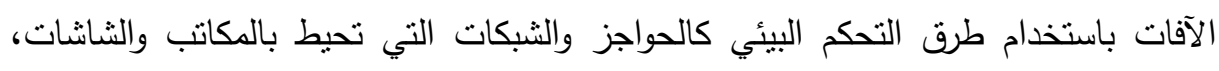

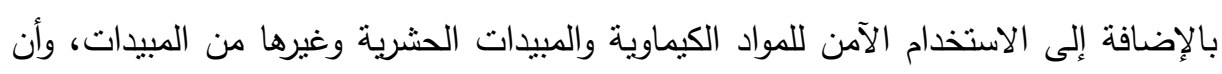

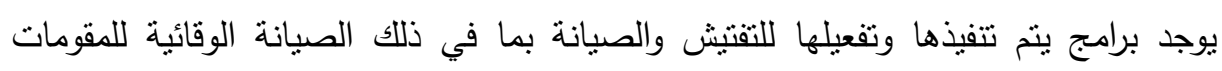

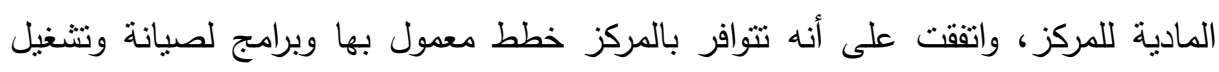

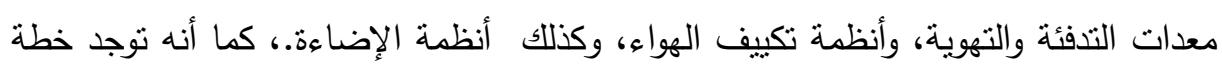
يتم تتفيذها للإدارة الآمنة للنفايات، كما اتفقت على أنه يوجد معاينة وتقييم دوري لنظم الإدارة

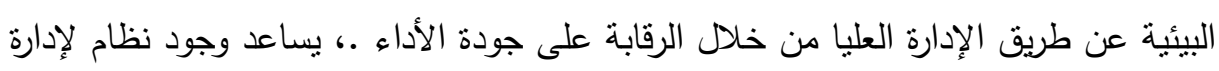
الجودة الثاملة في تطبيق نظم الإدارة البيئة. وبالرغم من ذلك فقد نوصلت الدراسة لاختلاف أراء عينات الدراسة فيما يتعلق بأنه يتم الاحتفاظ بسجلات الحضور من تعليم وتدريب العاملين في السلامة ومسائل الجودة البيئية.، وقد كانت أراء عينة المشاركين من الجانب الاداري بالمركز أكثر تساهلاً فيما يتعلق بأهمية أنه هناك علاقة جوهرية بين جوده الخدمة المقدمة وبين رضا العملاء والمستقيدين. 


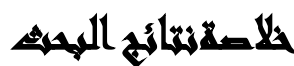

وقد توصل الباحثّن الي مجموعة من النتائج والتوصيات التي يمكن تطبيقها علي المراكز والوحدات ذات الطابع الخاص بجامعة عين شمس بل والجامعات والهيئات الخدمية

ا- إن أداء الخدمات يجب أن يأخذ فى الاعتبار عدة معايير بيئية تتصل بالتكلفة والكفاءة والفعالية والعدالة، وهذه المعايير هى التى تحدد إلى أى مستوى سيتم إنتاج وتقديم

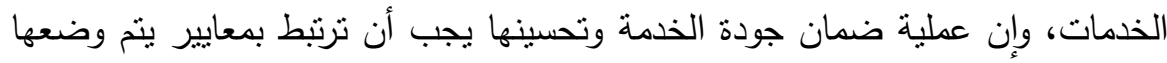
من المتخصصين والمنتفعين والمجتمع ويتفق هذا مع دراسة خطاب (T ( ب).

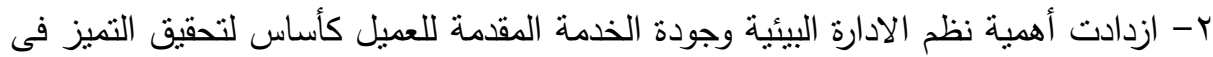

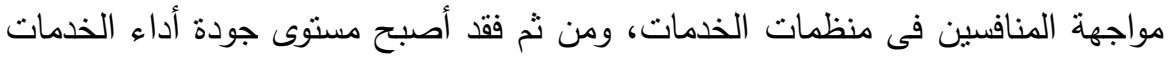
أحد الأسلحة التتافسية القوية فى تأمين الاستمرار والنمو للمنظمات الخدمية.

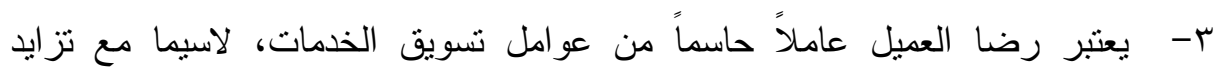

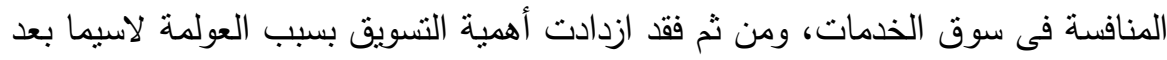

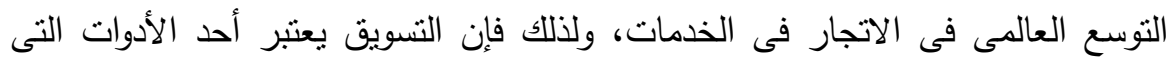
تجعل الوحدات ذات الطابع الخاص تحقق أهدافها بصورة أكثر كفاءة وفاعلية وبأقل تكلفة

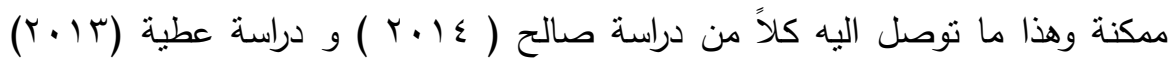

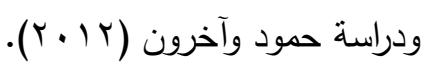

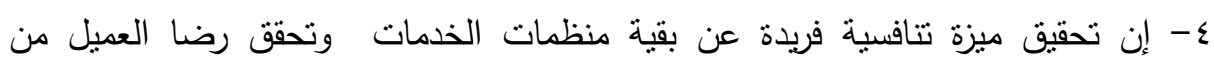
المبررات التى تدعو إلى الإهتمام بتقديم خدمة متميزة للمنتفعين وتطبيق نظم الادارة البيئية

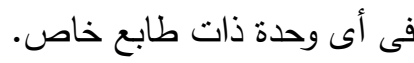
ه- إن النطبيق السليم لنظم الادارة البيئية يمكن أن يساهم مساهمة كبيرة فى استخدام موارد

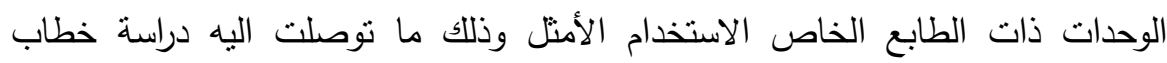




\section{تمصيامت الدواسمة}

يقدم الباحثون فيما يلي مجموعة من التوصيات في ضوء نتائج الدراسة والتي من شأنها

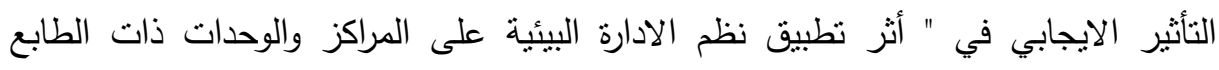
الخاص بالجامعة " وذللك على النحو التالي:

جدول رقم(؛ ): يوضح توصيات الدراسة وخطوات التطبيق وجهة التنفيذ

\begin{tabular}{|c|c|c|c|c|}
\hline الزمني & التفهيذ & خطوات التطبيق & التوصية & p \\
\hline مستمرة & - العليا. & 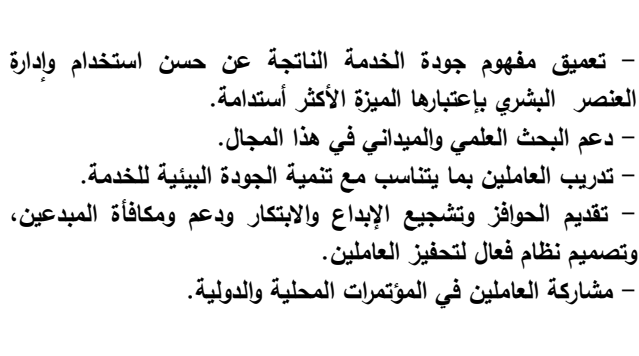 & 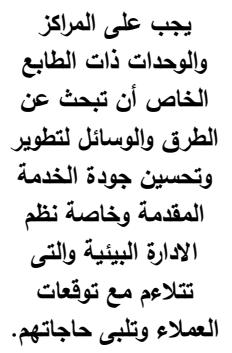 & 1 \\
\hline مستمرة. & 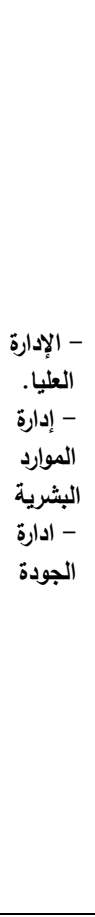 & 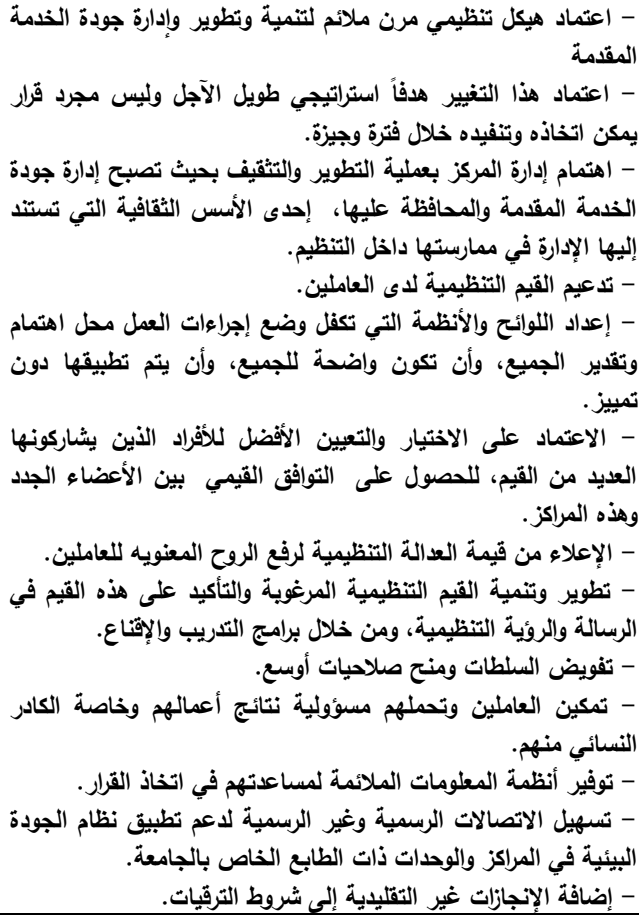 & 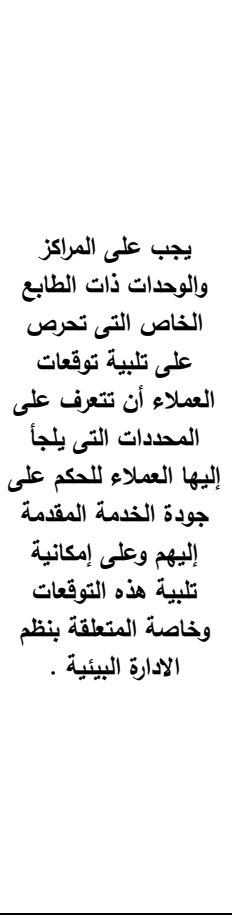 & r \\
\hline
\end{tabular}

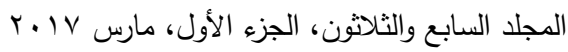


تابع جدول رقم(§ ): يوضح توصيات الدراسة وخطوات التطبيق وجهة التتفيذ

\begin{tabular}{||l|c|r|c|c|c||}
\hline \hline \\
\end{tabular}

\section{2all}

أحمد سعيد خليل(911 () ): مشروع مقترح لجامعة بيئية فى صعيد مصر ، رسالة دكتوراه غير

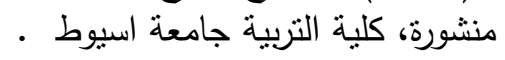

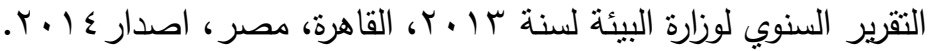

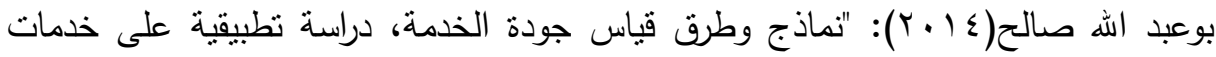

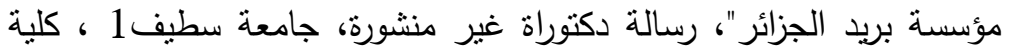

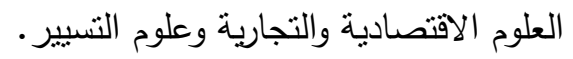

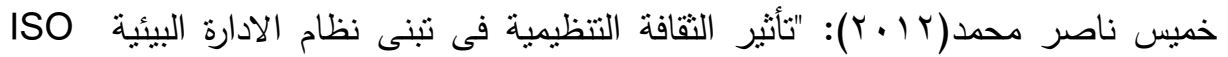

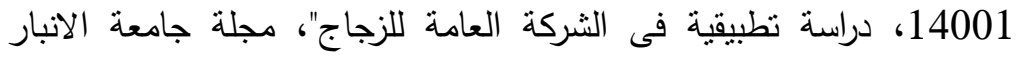

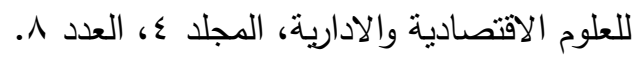




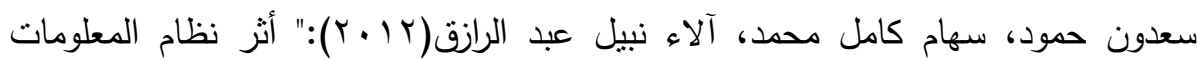

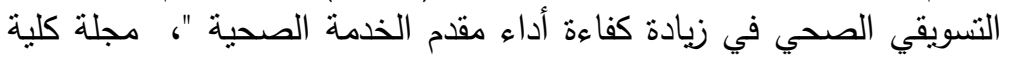
بغداد للعلوم الاقتصادية الجامعة، العدد الثاني والثلاثون.

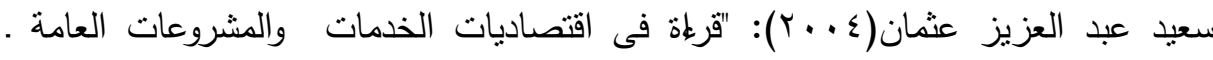
دراسة نظرية تطبيقية"، الدار الجامعية، الإسكندرية.

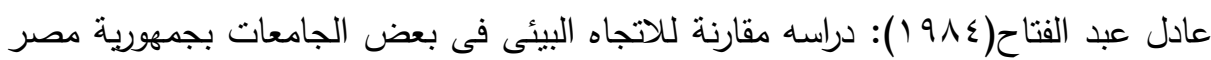
العربية والولايات المتحدة، رسالة دكتوراه غير منشورة، كلية التربية، جامعة التهات

$$
\text { • عين شمس ولايات }
$$

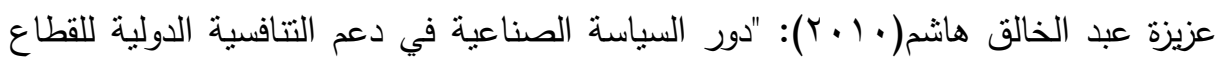

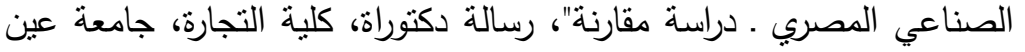

$$
\text { شمس، القاهرة. }
$$

عبد الرعوف محمد(ب99 (1)): " الجامعة والبيئة دراسة للدور البيئي لجامعة طنطا "، رسالة دكتوراه غير منشورة، كلية التربية، جامعة طنط

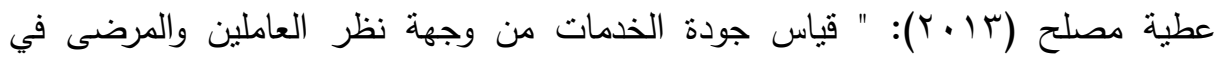

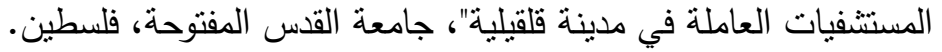

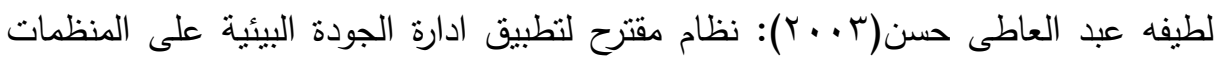

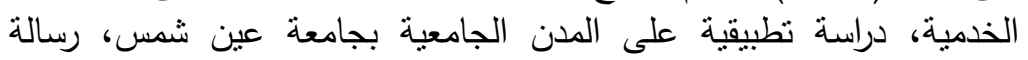

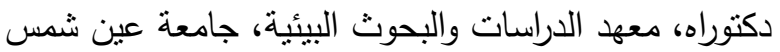

محمد ابراهيم عطوه مجاهد(1917): دور الجامعهد في خدمه البيئة، رساله دكتوراه غير منشوره، كليه التربيه جامعه المنصوره

محمد خطاب(7 1 ب): "قياس أثر تطبيق نظام الجودة البيئية علي تسويق الخدمات الطبية -

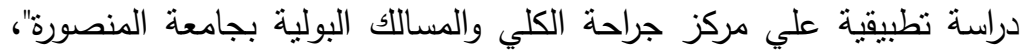

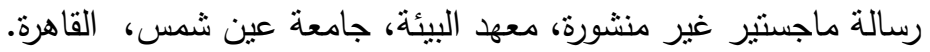

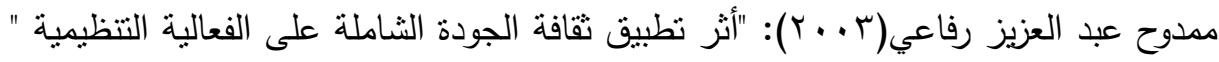

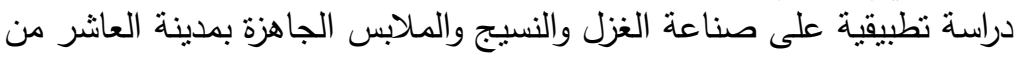

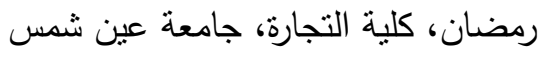

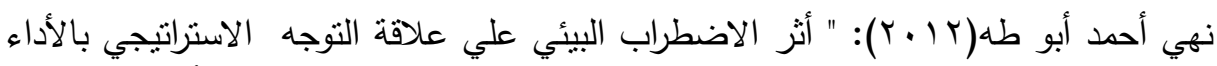

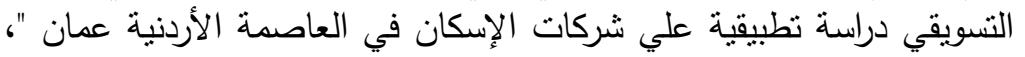

رسالة ماجستير غير منشورة، جامعة الثرق الأوسط، كلية الأعمال، الأردن الأرني

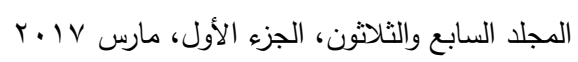




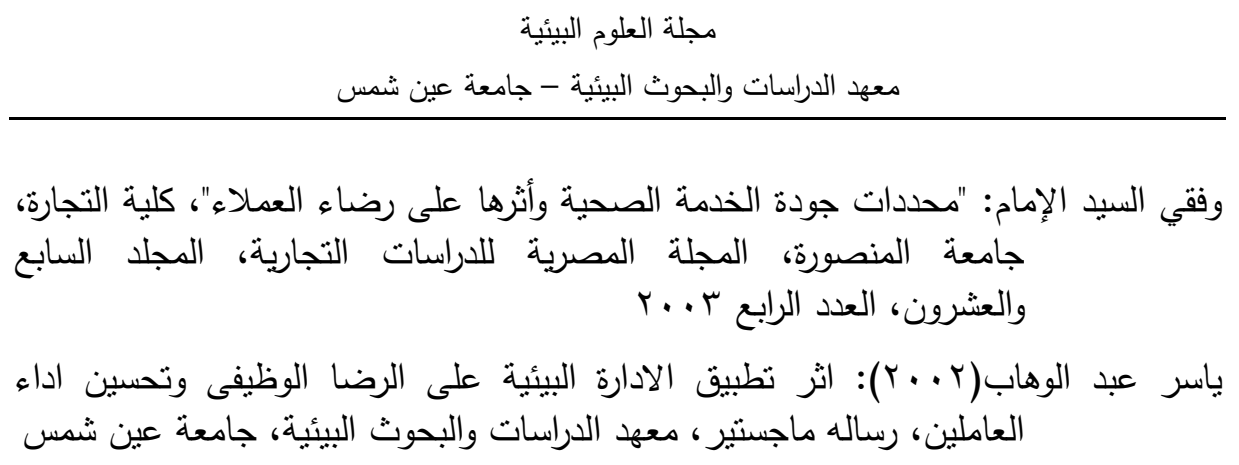

Crow, R., Storey, L., and Page, H., (2003), "The measurement of patient satisfaction: Implications for health service delivery through a systematic review of the conceptual, methodological and empirical literature", Health Technology Assessment,6(32).

Eleuch, Amira ep Koubaa, (2011), "Healthcare service quality perception in Japan", International Journal of Health Care Quality Assurance, Volume 24, Number 6, 2011 , pp. 417429(13), Emerald Group Publishing Limited.

Kotler , Philip and Armstrong Gory, Marketing Management Analysis , planning , Implementation and Control , Hall Engle wood cliffs , New Jersy, 1994.

Padhy, Prasanta Kumar \& Padhy, Prasanta Kumar (2010), "Patient Satisfaction and Marketing Effectiveness in Selected Large Hospitals in India" Berhampur University , Vishwa Vishwani Institute of Systems \& Management.

Williams, B., (1994), "Patient Satisfaction: a Valid Concept", Social Science Medical, Vol.38, No.4, PP 509-516. 


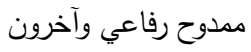

\title{
MEASURING THE IMPACT OF THE APPLICATION \\ OF ENVIRONMENTAL MANAGEMENT SYSTEMS \\ ON THE CENTERS AND UNITS OF SPECIAL \\ CHARACTR OF THE UNIVERST \\ (AN APPLIED STUDY ON AIN SHAMS \\ UNIVERSITY)
}

\author{
Refaiy, M. ${ }^{(1)}$; El Shahat, Nehal, M. F. ${ }^{(2)}$; Khatab, M. ${ }^{(1)}$ \\ and Ahmed, Heba ${ }^{(3)}$
}

1) Faculty of Commerce, Ain Shams University. 2) Institute of environmental studies and Research. Ain Shams University. 3) Ain Shams University.

\begin{abstract}
The purpose of this research study and the reality of services centers and units of a special nature and to identify the types and the observance of the environmental impact in the administrative and marketing process, and also aims to study the reality of EMS units of a special nature by seeking the views and opinions of the administrative leaders and workers in these units, and is the research problem in the absence of a clear policy making there are not a whole vision of the employees on the goals to be achieved and this and that del indicated by double-dip in the application of general quality and environmental management systems and global standards for special quality systems, which have become an inevitable force now in order to keep pace with global developments stunning and exit of the universities of the crucible local to compete for the world and find us a place at the universities of the world map, which represents a problem of this study, and adopted a researcher in this study, the combination of inductive and deductive approach, through theoretical study method and field study, it conducted researcher analyzing data using Kruskal and Las test for each

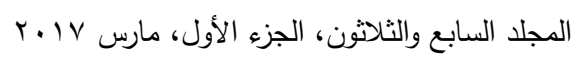


question questions List survey to test the hypotheses of the study using a sample consisting of 183 individuals study represent a sample of the study "a number of correct forms that have been recovered," has reached a researcher to a set of findings and recommendations that can be applied to the centers and units of a special nature, Ain Shams University, and even universities and bodies service in Egypt, and it was most important that the performance of services must take into account several environmental standards related to cost, efficiency and effectiveness, justice, and these standards are determined to any level will be the production and delivery of services.. 